\title{
Performance Analysis of a Modular Small-Diameter Air Distribution System
}

Andrew Poerschke IBACOS, Inc.

Armin Rudd

ABT Systems, LLC

March 2016 


\begin{abstract}
NOTICE
This report was prepared as an account of work sponsored by an agency of the United States government. Neither the United States government nor any agency thereof, nor any of their employees, subcontractors, or affiliated partners makes any warranty, express or implied, or assumes any legal liability or responsibility for the accuracy, completeness, or usefulness of any information, apparatus, product, or process disclosed, or represents that its use would not infringe privately owned rights. Reference herein to any specific commercial product, process, or service by trade name, trademark, manufacturer, or otherwise does not necessarily constitute or imply its endorsement, recommendation, or favoring by the United States government or any agency thereof. The views and opinions of authors expressed herein do not necessarily state or reflect those of the United States government or any agency thereof.
\end{abstract}

Available electronically at SciTech Connect http:/www.osti.gov/scitech

Available for a processing fee to U.S. Department of Energy

and its contractors, in paper, from:

U.S. Department of Energy

Office of Scientific and Technical Information

P.O. Box 62

Oak Ridge, TN 37831-0062

OSTI http://www.osti.gov

Phone: 865.576 .8401

Fax: 865.576.5728

Email: reports@osti.gov

Available for sale to the public, in paper, from:

U.S. Department of Commerce

National Technical Information Service

5301 Shawnee Road

Alexandria, VA 22312

NTIS http://www.ntis.gov

Phone: 800.553 .6847 or 703.605 .6000

Fax: 703.605.6900

Email: orders@ntis.gov 


\title{
Performance Analysis of a Modular Small-Diameter Air Distribution System
}

\author{
Prepared for: \\ The National Renewable Energy Laboratory \\ On behalf of the U.S. Department of Energy's Building America Program \\ Office of Energy Efficiency and Renewable Energy \\ 15013 Denver West Parkway \\ Golden, CO 80401 \\ NREL Contract No. DE-AC36-08GO28308 \\ Prepared by: \\ Andrew Poerschke \\ IBACOS, Inc. \\ 2214 Liberty Avenue \\ Pittsburgh, PA 15222 \\ Armin Rudd \\ ABT Systems, LLC \\ 726 E. Maple Street \\ Annville, PA 17003 \\ NREL Technical Monitor: Stacey Rothgeb \\ Prepared under Subcontract No. KNDJ-0-40341-05
}

March 2016 
The work presented in this report does not represent performance of any product relative to regulated minimum efficiency requirements.

The laboratory and/or field sites used for this work are not certified rating test facilities. The conditions and methods under which products were characterized for this work differ from standard rating conditions, as described.

Because the methods and conditions differ, the reported results are not comparable to rated product performance and should only be used to estimate performance under the measured conditions. 


\section{Contents}

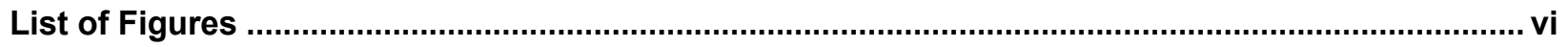

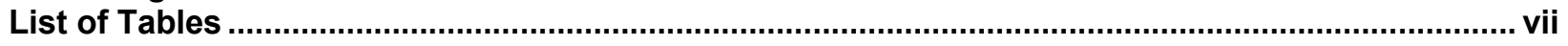

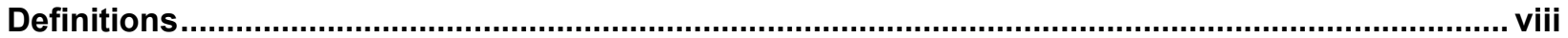

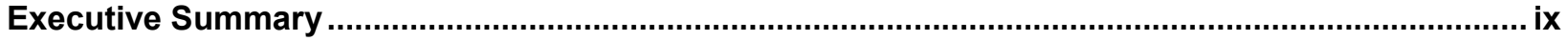

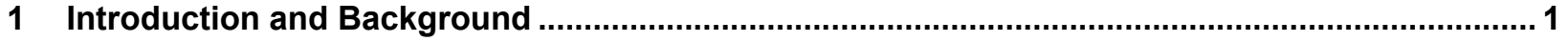

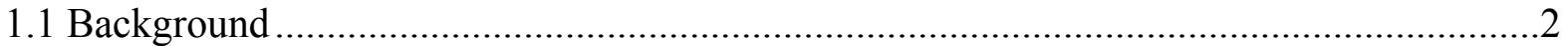

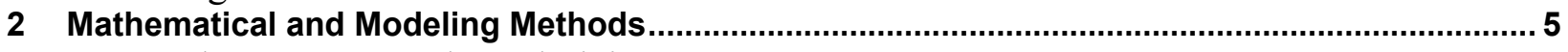

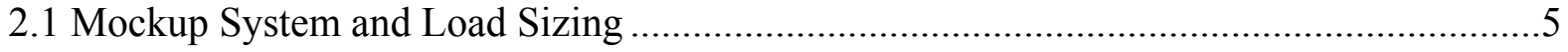

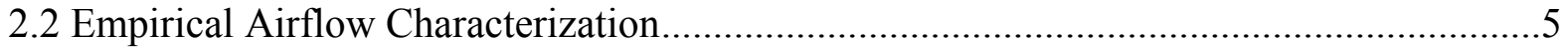

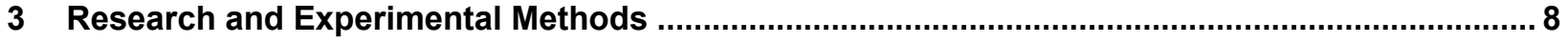

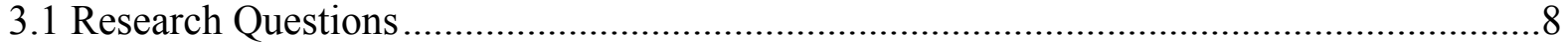

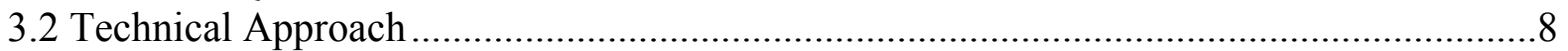

3.3 Air Handling Unit, Plenum, and Duct Runout Configurations and Construction ..............8

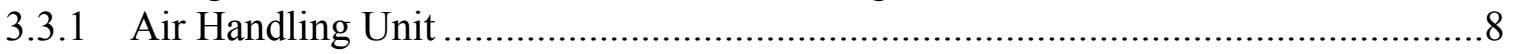

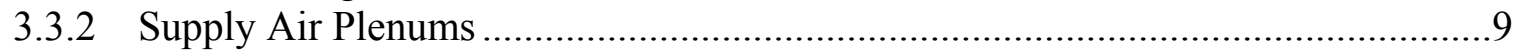

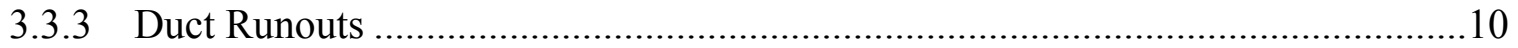

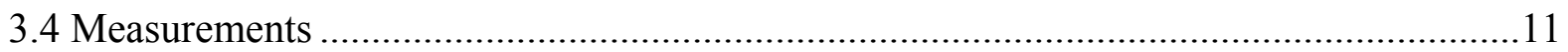

3.4.1 Measurement of Differential Pressure ............................................................... 12

3.4.2 Measurement of Total System Airflow.............................................................12

3.4.3 Measurement and Calculation of Runout Duct Airflow ..................................... 12

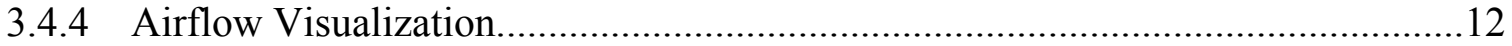

3.4.5 Measurement of Sound Level ........................................................................ 12

3.4.6 Measurement of Air Handling Unit Power .................................................. 13

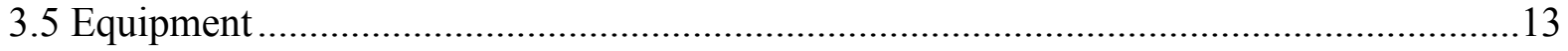

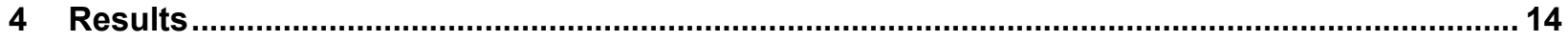

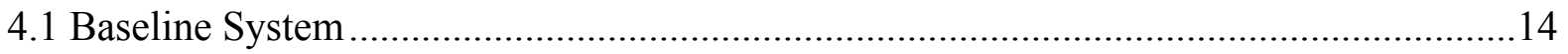

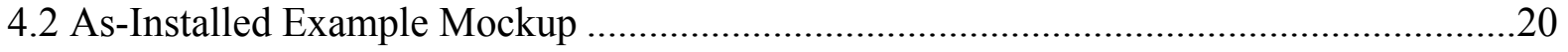

4.3 Measured Results and Air Conditioning Contractors of America Manual D...................24

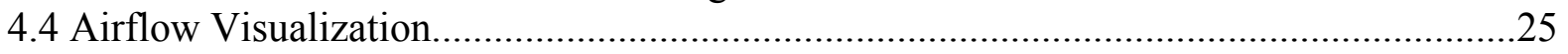

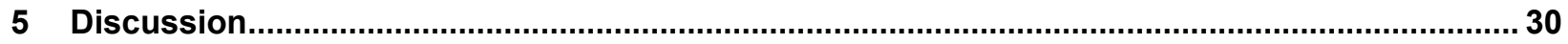

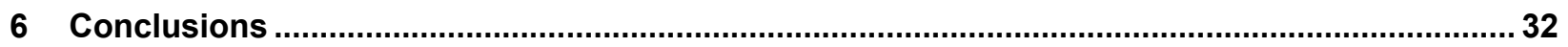

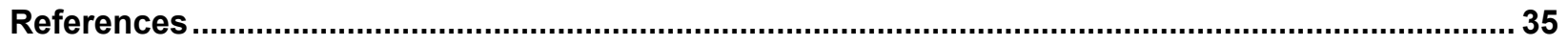

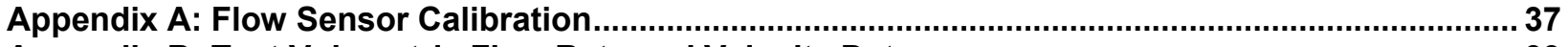

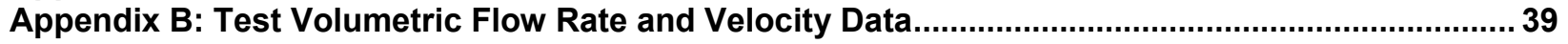




\section{List of Figures}

Figure 1. A small-diameter manifold (left) versus a traditional, centrally ducted system (right) ....... 2

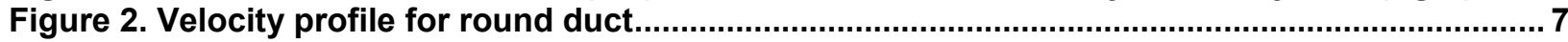

Figure 3. Using an adjustable-hole saw to cut the manifold outlets ................................................. 9

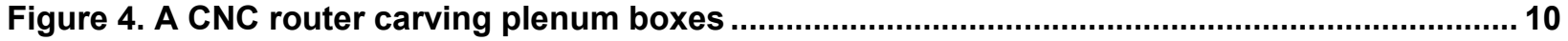

Figure 5. Testing a side outlet manifold configuration ..................................................................... 11

Figure 6. Duct testing mockup for an example case, showing the duct numbers...........................11

Figure 7. Diagram of duct runout modifications.......................................................................... 14

Figure 8. Duct airflow deviation for 2-in. manifold boxes-Box 1 (top) and Box 2 (bottom) ............ 15

Figure 9. Duct airflow deviation for 2-in. manifold boxes-Box 3 (top) and Box 4 (bottom) ............ 16

Figure 10. Duct airflow deviation for 2.5-in. manifold boxes-Box 5 (top) and Box 6 (bottom) ....... 17

Figure 11. Duct airflow deviation for 2.5-in. manifold boxes-Box 7 (top) and Box 8 (bottom) ....... 18

Figure 12. Duct airflow deviation for MSHP manifold boxes-Box 9 (top) and Box 10 (bottom) ..... 19

Figure 13. Example house floor plan for mockup (second floor of the home) ................................. 20

Figure 14. Airflow deviation of the mockup duct system relative to duct length.............................21

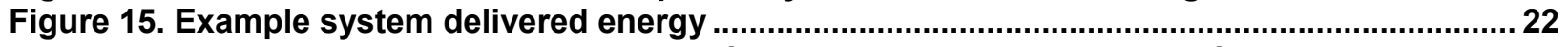

Figure 16. Measured duct pressure versus airflow relationship and common fan curves ............... 23

Figure 17. Mockup duct system showing elbows .......................................................................25

Figure 18. Flow in top-down configuration after $1 \mathrm{~s}$ (top series) and $4 \mathrm{~s}$ (bottom series) ................ 26

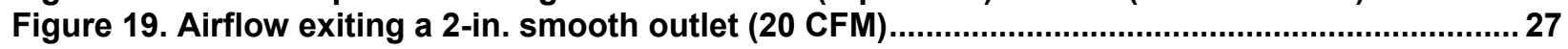

Unless otherwise noted, all figures and photos were created by IBACOS. 


\section{List of Tables}

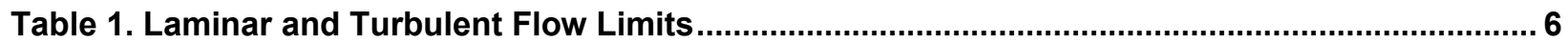

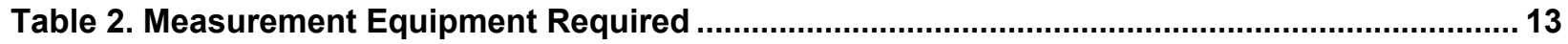

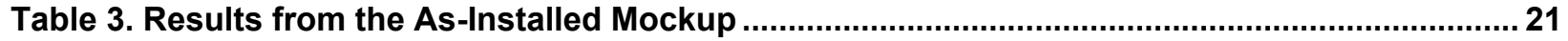

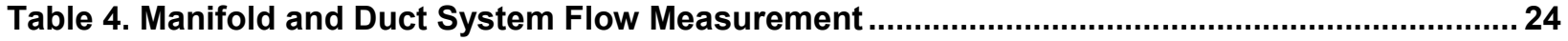

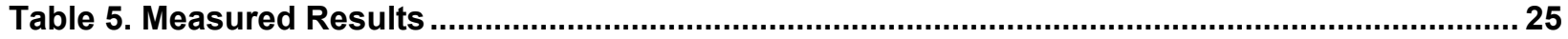

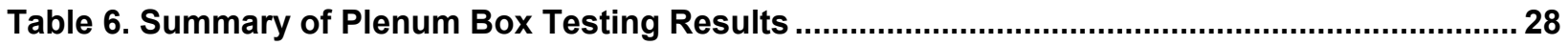

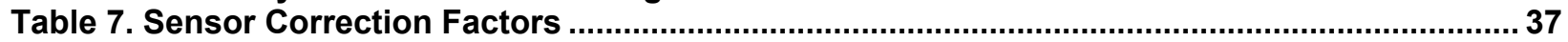

Table 8. Velocity Measurement and Calculation Comparison........................................................... 37

Table 9. Sensitivity of Flow Measurement to Sensor Angle ............................................................... 38

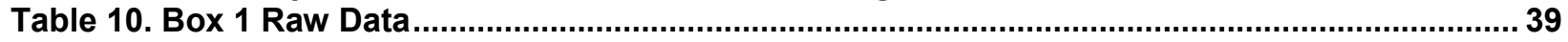

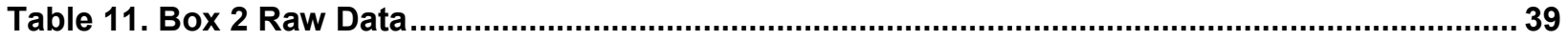

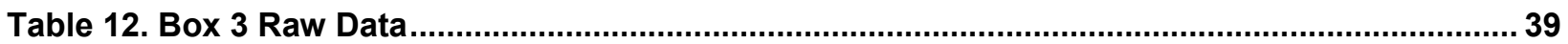

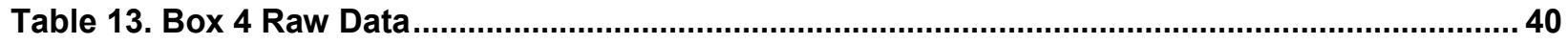

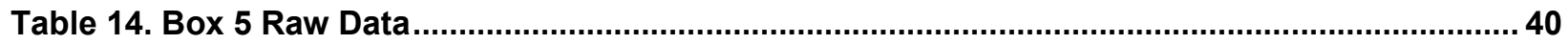

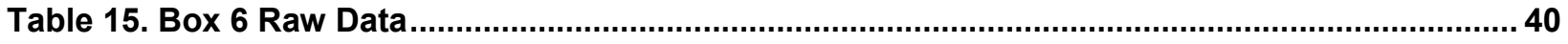

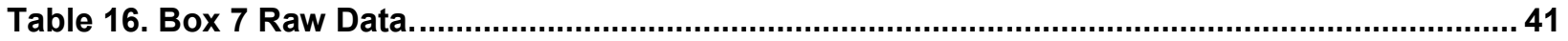

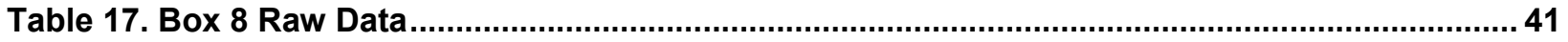

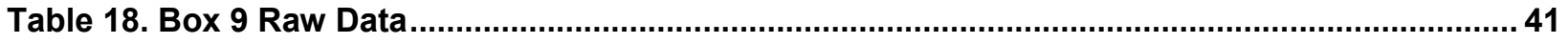

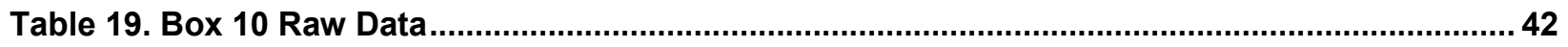

Unless otherwise noted, all tables were created by IBACOS. 


\section{Definitions}

ACCA

AHU

$\mathrm{Btu} / \mathrm{h}$

CFM

HVAC

ICC

MSHP

$\mathrm{NC}$

PVC

SP
Air Conditioning Contractors of America

Air handling unit

British thermal units per hour

Cubic feet per minute

Heating, ventilating, and air conditioning

International Code Council

Mini-split heat pump

Noise criteria

Polyvinyl chloride

Static pressure 


\section{Executive Summary}

Previous work by the U.S. Department of Energy's Building America research team IBACOS and other Building America teams has shown that for all but the most simple house geometries conditioned air must be supplied to each thermal zone. Standard methods that use traditional duct geometries have several drawbacks, which include difficulty in bringing ductwork into conditioned space because of the necessary bulkheads, long duct runs, large duct sizes, and a larger surface area to seal. The homebuilding industry is interested in alternative spaceconditioning systems that can address these concerns and provide thermal comfort and energy efficiency.

This report investigates the feasibility of using a home-run manifold small-diameter duct system to provide space-conditioning air to individual thermal zones in a low-load home. This compact layout allows duct systems to easily be brought within conditioned space via interior partition walls. Centrally locating the air handling unit in the house significantly reduces duct lengths. The plenum box is designed so that each connected duct receives a similar amount of airflowregardless of its position on the box. Furthermore, within a reasonable set of length restrictions each duct continues to receive similar airflow. For the plenum box investigated in this report, duct runs longer than $10 \mathrm{ft}$ and shorter than $25 \mathrm{ft}$ had airflows of 20-16 cubic feet per minute (CFM).

The design method uses an additive approach to reach the total required zonal airflow. Once the airflow rate needed to satisfy the thermal load of a zone has been determined, the total number of duct runs to a zone can be calculated by dividing the required airflow by the standard airflow from each duct. For example, if a zone requires $60 \mathrm{CFM}$ of conditioned air to meet the load and the base airflow from each duct is 20 CFM, three ducts would be specified for that zone. This method differs from that of traditional duct system design, which relies on varying the diameter of the trunk and branch ductwork to manage static pressure (SP) and to supply the desired airflow to each thermal zone. The additive approach greatly simplifies the design effort and reduces the potential for duct design mistakes.

By setting up equivalent branch runouts and measuring the air velocity in a representative sample of ducts, the research team found two plenum box designs that maintained satisfactory uniform airflow from each branch duct $( \pm 5 \%)$.

After choosing the ideal box geometry, a full mockup duct design was then laid out for laboratory testing of airflow, SP, and power consumption of a ducted mini-split heat pump (MSHP) blower. The duct system was designed such that it could be installed in - and meet the airflow requirements of - the second floor of an example 3,600- $\mathrm{ft}^{2}$ production home.

Measured results indicate that this plenum design can satisfy the heating load $(8,280 \mathrm{Btu} / \mathrm{h})$. However, the total airflow falls short of satisfying the cooling load. The SP inside the plenum box, which is 51.5 Pascals ( 0.21 in. water column), limited the total airflow of the MSHP blower, which limits the total thermal capacity. A slightly oversized MSHP ducted unit could overcome the elevated SP. Fan energy consumption is kept to 0.22 watts per cubic feet per minute or lower by using short duct runs and smooth duct material. 


\section{Introduction and Background}

Previous work by the U.S. Department of Energy's Building America research team IBACOS and other Building America teams has shown that for all but the simplest house geometries, conditioned air must be supplied to each room to maintain comfort. Homebuilders and heating, ventilating, and air-conditioning (HVAC) system installers need an inexpensive way to reliably supply the correct amount of conditioned air to individual rooms without performing complex duct system design calculations. Current practices for designing and installing air delivery systems have many possible failure modes:

- Errors in calculating load

- Incorrect equipment selection

- Errors in duct system design

- Incorrect in-field duct and register/grille component selection

- Poor installation of ductwork, which causes airflow restriction

- Poor sealing of ductwork and connections

- Inefficient operation due to duct runs in unconditioned space

- Failure to commission and properly balance the installed system.

This report looks at the performance of a small-diameter modular air distribution system with home-run ductwork, which can reduce the risk of these failure modes that lead to comfort problems. Home-run ductwork refers to individual branch ducts that leave a central distribution manifold and have a predictable airflow associated with only the diameter of the duct. Figure 1 compares the proposed manifold duct layout to a traditional, centrally ducted air handling unit (AHU). In theory, with a mature home-run system design, an inspector could simply count the number of home-run ducts and sum the total airflow to a given room. This number then could be compared to an airflow specification based on the calculated load.

Low-load homes built to 2012 International Energy Conservation Code (ICC 2012) energy standards are appropriate targets for this technology, because their small envelope loads greatly reduce the magnitude of airflow needed and provide opportunities to bring the small-diameter ductwork into conditioned space. Mini-split heat pump (MSHP) manufacturers are rapidly introducing high-efficiency, ducted units that can be used to condition one or more rooms as a zonal distributed space-conditioning strategy instead of a full central system. Zonal systems are intended to serve only a few rooms that are close in physical proximity to significantly reduce the required length of duct runs and the pressure drop associated with long duct runs. These systems increase the feasibility of using small-diameter duct runs. 


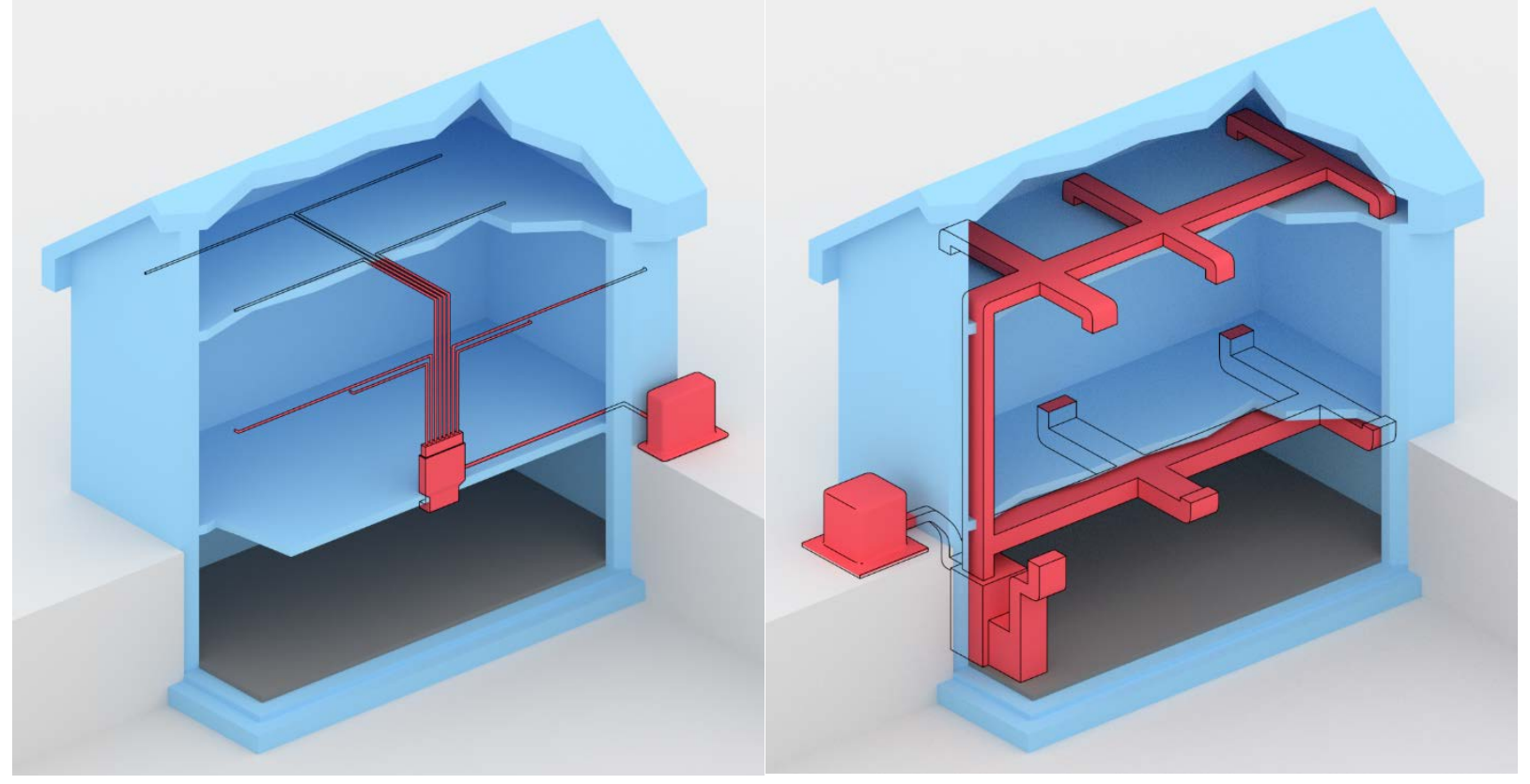

Figure 1. A small-diameter manifold (left) versus a traditional, centrally ducted system (right)

\subsection{Background}

The difficulties with creating central space-conditioning systems (i.e., design, balancing, operation, supply outlet locations, fan operation strategies) for low- and very-low-load homes have been well documented through modeling and field measurements (IBACOS 2006a, 2006b, 2007; Rittelmann 2008; Broniek 2008). Aldrich (2009) documented the significant impact internal gains of occupants and simple electronics can have in the heating season to offset loads in houses with single-point supply heating systems and minimal distribution systems. Results from studies conducted at the IBACOS unoccupied test houses in Pittsburgh, Pennsylvania (Poerschke and Stecher 2014), and Fresno, California (Stecher and Poerschke 2013) have shown that in well-insulated homes with open floor plans, sufficient temperature uniformity meeting Air Conditioning Contractors of America (ACCA) Manual RS standards (Rutkowski 1997) can be achieved in the open space by providing space conditioning from a single outlet location.

Although central, open spaces can be straightforward to condition with simple systems, individual rooms that are isolated from the main open space present a challenge for providing comfort. The effect of solar heat gain can be pronounced in these instances. Sun-tempered houses on Martha's Vineyard, Massachusetts, showed significant fluctuations in temperatures at the first-floor main spaces and second-floor bedrooms with only east- or west-facing windows (Stecher et al. 2012). Results from the IBACOS unoccupied test house in Pittsburgh, Pennsylvania (Poerschke and Stecher 2014), also showed the expected result that bedrooms with significant southern and western glazing tend to overheat when the rest of the house is close to the set point temperature.

IBACOS studied passive air transfer from the central spaces to bedrooms with doors open and doors closed in its two unoccupied test houses: one in Fresno, California (Stecher and Poerschke 2013), and one in Pittsburgh, Pennsylvania (Poerschke and Stecher 2014). With interior partition doors open, rooms maintained a uniform temperature. However, when interior partition doors 
were closed, passive air inlets provided poor communication between the room and the space containing the thermostat, which resulted in room-to-room temperature differences beyond ACCA Manual RS recommendations (Rutkowski 1997). Measured data (Aldrich 2010) indicated that limited fan-forced supply from the first-floor main space to the second-floor bedrooms with doors closed generally can maintain comfort conditions from a single source of heating in the main living space in a cold climate during the heating season. Aldrich (2010) and Townsend et al. (2009) indicated that some level of active air mixing throughout the house also is necessary to ensure fresh ventilation air reaches all spaces.

One possible solution is to provide individual room space conditioning (e.g., individual room fan coils or heat pump units) that can maintain desired temperatures independently in each room. Although design research has been performed on such systems (Drost and Wegeng 1996), IBACOS has not found market-acceptable residential units in the capacity $(1,000-3,000 \mathrm{Btu} / \mathrm{h})$ that is necessary to provide individual room conditioning while integrating with a central control system.

The performance of ductless MSHP units has been documented by several U.S. Department of Energy Building America teams. Findings by Ueno and Loomis (2014) indicate that even small homes required at least two indoor head units to mitigate stratification between floors. The largest house in the Ueno and Loomis (2014) study $\left(2,300 \mathrm{ft}^{2}\right)$, which is closer in size to typical production homes, required three additional indoor head units after comfort problems were reported in the most geometrically remote rooms.

As mentioned, IBACOS has conducted alternative HVAC system research in houses that meet the Building America 50\% energy savings targets through 2012 at unoccupied test houses in Fresno, California (Stecher and Poerschke 2013), and Pittsburgh, Pennsylvania (Poerschke and Stecher 2014). In light of that research and other past IBACOS research (IBACOS 2006a, 2006b, 2007; Rittelmann 2008; Broniek 2008), as well as the research by others as cited above, IBACOS has concluded that for all but the simplest house plans, some form of conditioned air distribution to each room is required to provide occupant comfort. More specifically, IBACOS reached the following conclusions:

- Because of uneven external and internal gains, individual rooms with closed doors may not achieve temperature uniformity (per ACCA Manual RS [Rutkowski 1997]) with only one thermostat, even with rightsized central systems. Production builders have communicated this concern to IBACOS, even with homes built at the 2012 International Energy Conservation Code levels of performance (ICC 2012).

- Variable output systems that can modulate capacity (Btu/h) and airflow rate (CFM) can provide superior occupant comfort and improved energy efficiency throughout the year.

- In homes with open floor plans, fewer points of supplied conditioned air can maintain temperature uniformity in the central living spaces to satisfy recommendations in ACCA Manual RS (Rutkowski 1997).

- Toe-to-head air temperature stratification, averaged throughout a low-load house, is rarely greater than $3^{\circ} \mathrm{F}$. 
- Bringing conventionally sized ductwork into conditioned space represents a significant challenge to production homebuilders.

- Passive heat transfer through open doors is a function of the door opening size, the size of any transitional spaces (e.g., a hallway), or other openings between the actively conditioned space and the room with no active conditioning, and the temperature difference of the room with no active conditioning.

- Based on occupant preferences, interior doors may remain open all day. However, from a passive air transfer standpoint, the worst-case scenario is a house with interior partition doors that are closed 24 hours per day.

- IBACOS believes the following issues must be resolved for production builders to begin to adopt new strategies and methodologies for space-conditioning systems in low-load houses:

○ Appropriate HVAC system responses (e.g., equipment, air distribution, controls) for new low-load homes are needed across peak load and nonpeak load conditions in all climate zones.

- Whole-house performance tradeoffs (e.g., thermal uniformity, efficiency, and cost) must be quantified when choosing between competing space-conditioning and ventilation system designs.

○ The technical merits of variable airflow output, small-duct space-conditioning systems must be compared to readily available alternatives from the perspectives of cost, performance (e.g., energy and system noise), and occupant comfort. Alternative system types include traditional centrally ducted systems, limited ducted distribution systems with fewer supply points, and point-source systems. 


\section{Mathematical and Modeling Methods}

The majority of the results from this project are based on laboratory measurements in two phases: (1) testing of various plenum box designs with similar duct runouts, and (2) testing of the best plenum box with a mockup duct runout. The research team performed an uncertainty analysis on individual measurements. The team also calibrated the laboratory measurements according to individual sensors and compared those measurements to expected fluid behavior.

\subsection{Mockup System and Load Sizing}

To design the duct layout for the sample mockup system, the team first performed a load sizing using Wrightsoft Version 13.0.10 on a two-story, slab-on-grade house design. The house design has many rooms that are distant from the main living space and is a challenge to condition with a single ducted system. A large house such as this ideally would have two HVAC systems - one on each floor. Based on this load sizing, the team determined the required airflow rates to meet the load. To best align with concurrent IBACOS work efforts, the team chose the house design based on the production house in Herk and Rapport (2015). The team then determined the number of duct runouts needed to satisfy this load based on the laboratory airflow testing results. A floor plan for this house can be found in Section 4 as Figure 13.

\subsection{Empirical Airflow Characterization}

The team wished to compare the measured airflow to the established fundamentals of fluid dynamics. A basic understanding of flow characteristics can be described by the Reynolds number. This number can predict whether a flow will be laminar or turbulent. In a round pipe, for Reynolds numbers less than 2,100, flows typically are laminar, whereas Reynolds numbers greater than 4,000 typically are turbulent (Munson et al. 2009). Reynolds numbers between 2,100 and 4,000 suggest that the flow is in an ill-defined "transition" region, and as such, empirical measurements must be made to characterize the flow. The team used Equation 1 to calculate the Reynolds number:

$$
\operatorname{Re}=\frac{\rho V D}{\mu}
$$

where

$R e=$ Reynolds number

$\rho=$ Density of fluid

$\mu=$ Dynamic viscosity

$V=$ Velocity

$D=$ Hydraulic diameter

For the 2-in. and 2.5-in. ducts considered in this project, the velocities shown in Table 1 dictate the transition between laminar and turbulent flows. For all but the lowest airflow rates, the flow 
was turbulent. Flow rates between the maximum laminar value and the minimum turbulent value are in a transition region where the exact state cannot be characterized with existing equations. The flows studied in this project are rarely in this region.

Table 1. Laminar and Turbulent Flow Limits

\begin{tabular}{l|c|c|c}
\hline & Unit & $\begin{array}{c}\text { Maximum } \\
\text { Laminar Flow }\end{array}$ & $\begin{array}{c}\text { Minimum } \\
\text { Turbulent Flow }\end{array}$ \\
\hline \multirow{2}{*}{ 2.5-in. Duct } & $\mathrm{ft} / \mathrm{min}$ & 99 & 189 \\
& $\mathrm{CFM}$ & 3.4 & 6.4 \\
\multirow{2}{*}{ 2-in. Duct } & $\mathrm{ft} / \mathrm{min}$ & 124 & 236 \\
& $\mathrm{CFM}$ & 2.7 & 5.2 \\
\hline
\end{tabular}

Because the air velocity was sampled at the centerline of each duct, an understanding of the airflow velocity profile was necessary to correlate measured air velocities to total duct flow rates. From Eq. 2, which is the equation for the empirical power-law velocity profile for turbulent flows (Munson et al. 2009), the team determined that the total average velocity was $85 \%$ of the centerline velocity. At the pipe centerline, the velocity is equal to the measured centerline value. As the distance from the centerline approaches the radius of the pipe, the velocity approaches zero. Figure 2 shows the profile for the 2-in.-diameter and 2.5-in.-diameter ducts.

$$
\frac{V_{x}}{V_{c}}=\left(1-\frac{r}{R}\right)^{1 / n}
$$

where

$V_{x}=$ Velocity at a distance from the centerline

$V_{c}=$ Velocity at the centerline

$r=$ Distance from the centerline

$R=$ Radius of the pipe

$n=$ Power law value, function of Reynolds number (typical value of 7 can be used) 


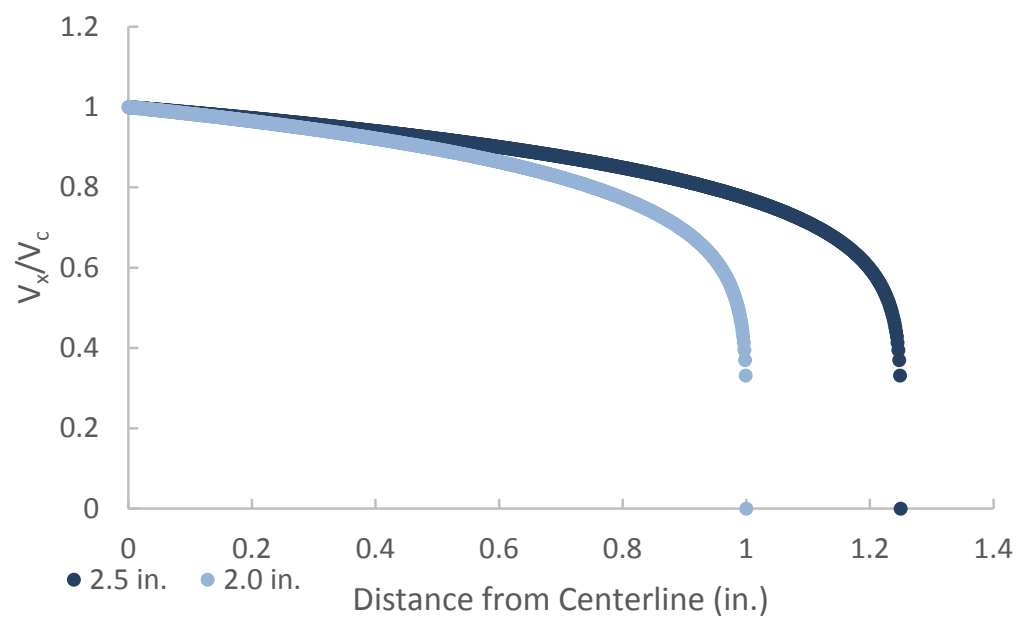

Figure 2. Velocity profile for round duct 


\section{Research and Experimental Methods}

\subsection{Research Questions}

The following research questions will be answered by this project:

- Can a strategy of additive, individual, small-diameter ducts (2-in. and 2.5-in. diameter) provide adequate airflow to give comfort in a low-load house?

- What are the fan energy tradeoffs and maximum recommended run lengths for smalldiameter ducts connected to small plenums?

- What load characteristics could each duct serve, and what other parameters (velocity, throw) are associated with such a system?

- What are the ideal configuration and geometry of a small plenum for a home-run smalldiameter duct system that would be adaptable to MSHP systems or small distributed central systems and that would supply equal airflow through each duct without balancing?

- What is the energy impact of locating ducts inside conditioned space relative to the higher fan energy needed to move the airflow under higher flow resistance?

\subsection{Technical Approach}

IBACOS assessed the performance of a small-diameter (2-in.-diameter and 2.5-in.-diameter) ducted air-distribution system. The research team constructed 10 mockup plenum boxes with small-duct runouts. Measurements were collected on each duct system configuration to establish airflow, velocity, and pressure drop. Then the team constructed the mockup duct system to mimic a system that could be installed in the house floor plan (shown later in Figure 13). The measured results for airflow and delivered energy were compared to calculated room loads.

IBACOS designed an ideal system layout for the house plan to provide the least complex installation. The duct layout was set up in the test facility (shown later in Figure 6). Duct performance characteristics were measured, including airflow, air velocity, pressure drop, and AHU fan power.

\subsection{Air Handling Unit, Plenum, and Duct Runout Configurations and Construction}

This section describes the configurations of the AHUs, supply plenums, and small-diameter duct runouts that extend from the supply plenum of the ideal duct system. Construction of the plenums with runout takeoffs is detailed. Technical data are provided in tables related to total system airflow, runout air velocity, runout airflow, number of runouts required to carry the total system airflow, and runout load capacity.

\subsubsection{Air Handling Unit}

Two types of AHUs made up the basic driver for the air-distribution systems: (1) a commercially available AHU made for ducting air from a 1-ton variable-capacity, variable-airflow MSHP system (Samsung EH035CAV, 265 to $370 \mathrm{CFM}$ ), and (2) a commercially available, usercontrolled, variable-speed blower that was suitable for testing purposes. 
The team also considered a third scenario in which a boost fan was installed in series with the main ducted MSHP AHU. The boost fan consisted of a Duct Blaster connected to the return plenum area of the ducted mini-split. Because the added duct system impeded the MSHP AHU from achieving its rated airflow, the boost fan was activated and ramped up so the total system airflow reached the rated airflow of the MSHP. The final mockup duct configuration was the only one tested with the additional boost fan.

Each AHU was mounted on a test wall setup with various plenum and duct configurations attached for testing. The test wall was designed to allow for efficient substitution of plenum boxes and duct systems.

\subsubsection{Supply Air Plenums}

Supply air plenum boxes were designed to be straightforward to construct and test. All plenum designs were simple rectangular boxes. Future testing may optimize the shape of the most promising box layouts.

The team constructed supply air plenums from 0.5-in.-thick cabinet-grade plywood. An adjustable-diameter hole saw was used to cut tight-fitting holes for connecting the polyvinyl chloride (PVC) ductwork (Figure 3), so no additional sealant would be needed.

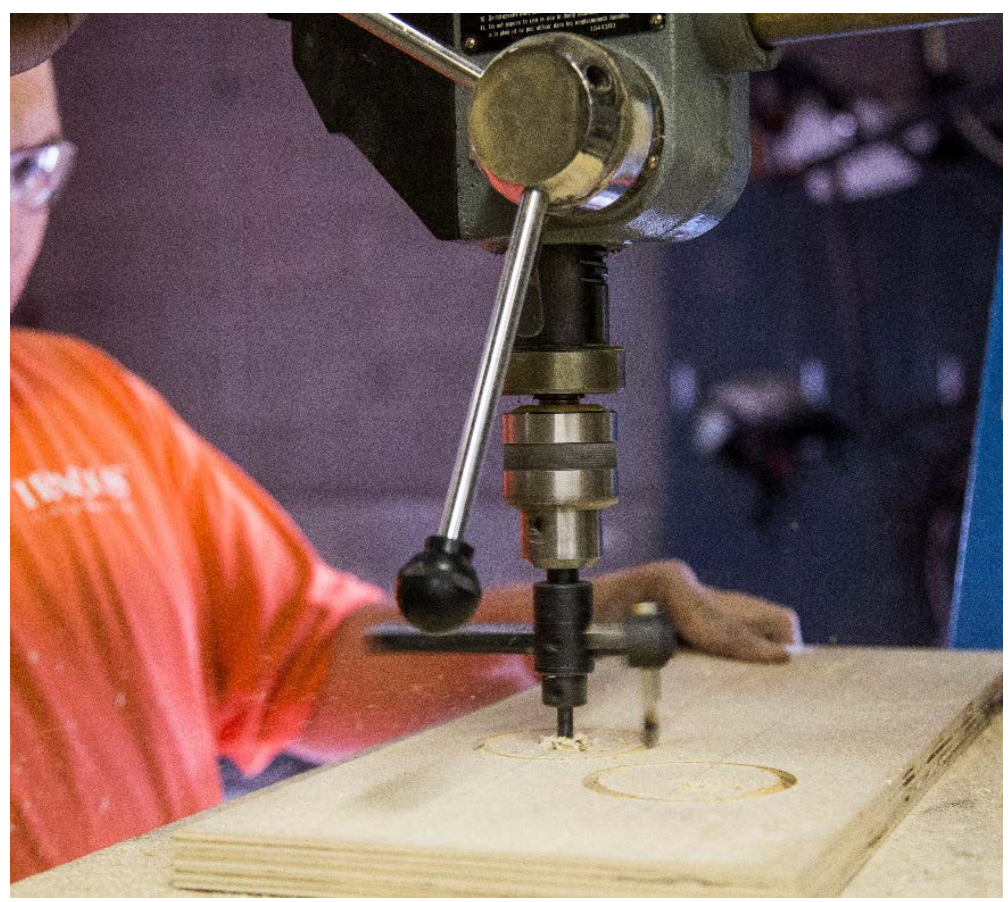

Figure 3. Using an adjustable-hole saw to cut the manifold outlets

The team used 0.25 -in. polycarbonate sheet on four sides to construct an additional set of duct boxes. The final two sides were constructed from plywood and painted a flat black. The team used computer numeric control $(\mathrm{CNC})$ equipment to make the cutouts of plastic and plywood to provide tight dimensional tolerances (Figure 4). Clear panels in the boxes enabled the team to use theatrical smoke to observe the airflow. A planar laser was shone through the bottom of the box to highlight a two-dimensional slice of the flow. 


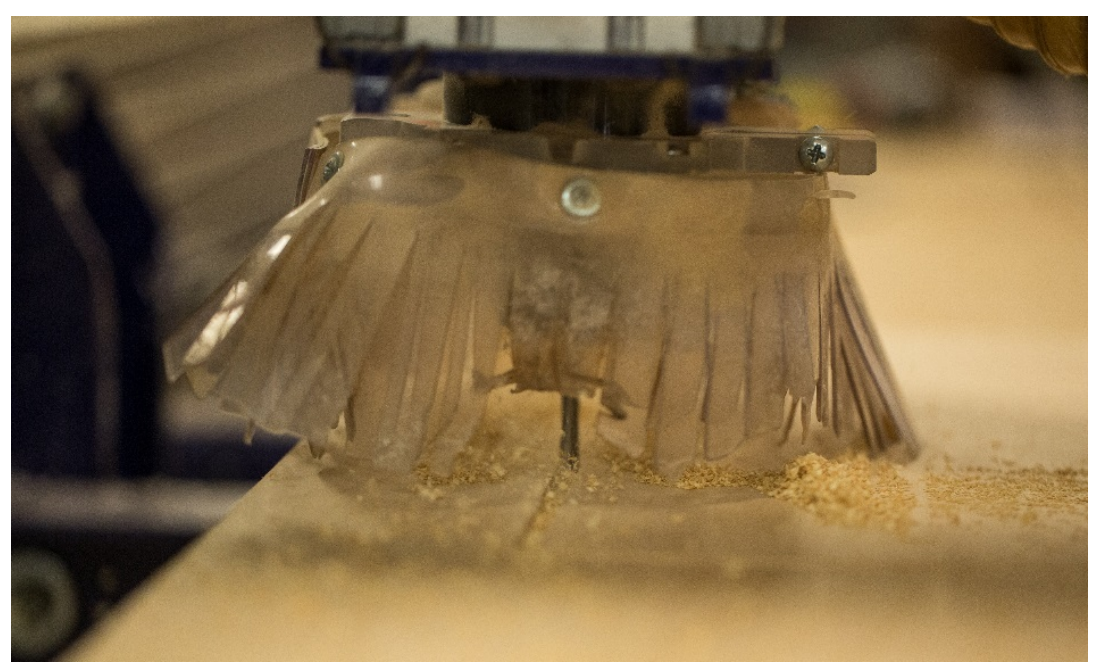

Figure 4. A CNC router carving plenum boxes

\subsubsection{Duct Runouts}

The team constructed the duct runouts from 2-in.-diameter and 2.5-in-diameter Schedule 40 PVC pipe. This material was chosen because of its low airflow resistance, ease of making leak-free joints, availability, and rigidity; the rigidity allows for easy setup of the mockup systems. ${ }^{1}$ The team installed each of the duct runouts to match the hole configuration of the respective duct box.

Then the team tested each plenum box in one of four configurations. First, to gather baseline data, the team connected ducts of equal length to each outlet. Next, the team considered three variations that were intended to change the resistance of each duct:

1. One duct run length was increased by a factor of 1.5 or 2 (increased resistance).

2. Several $90^{\circ}$ bends were added to some of the duct runs (increased resistance).

3. One duct length was reduced by a factor of 2 (halved) (decreased resistance).

Figure 5 shows testing of a side outlet manifold configuration. Figure 6 shows the example duct system testing setup for the chosen house. In testing the example duct layout, ductwork was bent in such a way that it would lie flat; however, in a real house, the ductwork would take a threedimensional shape.

\footnotetext{
${ }^{1}$ Another ongoing IBACOS effort is coordinating with industry stakeholders and the codes community to make PVC ductwork code-approved for air delivery.
} 


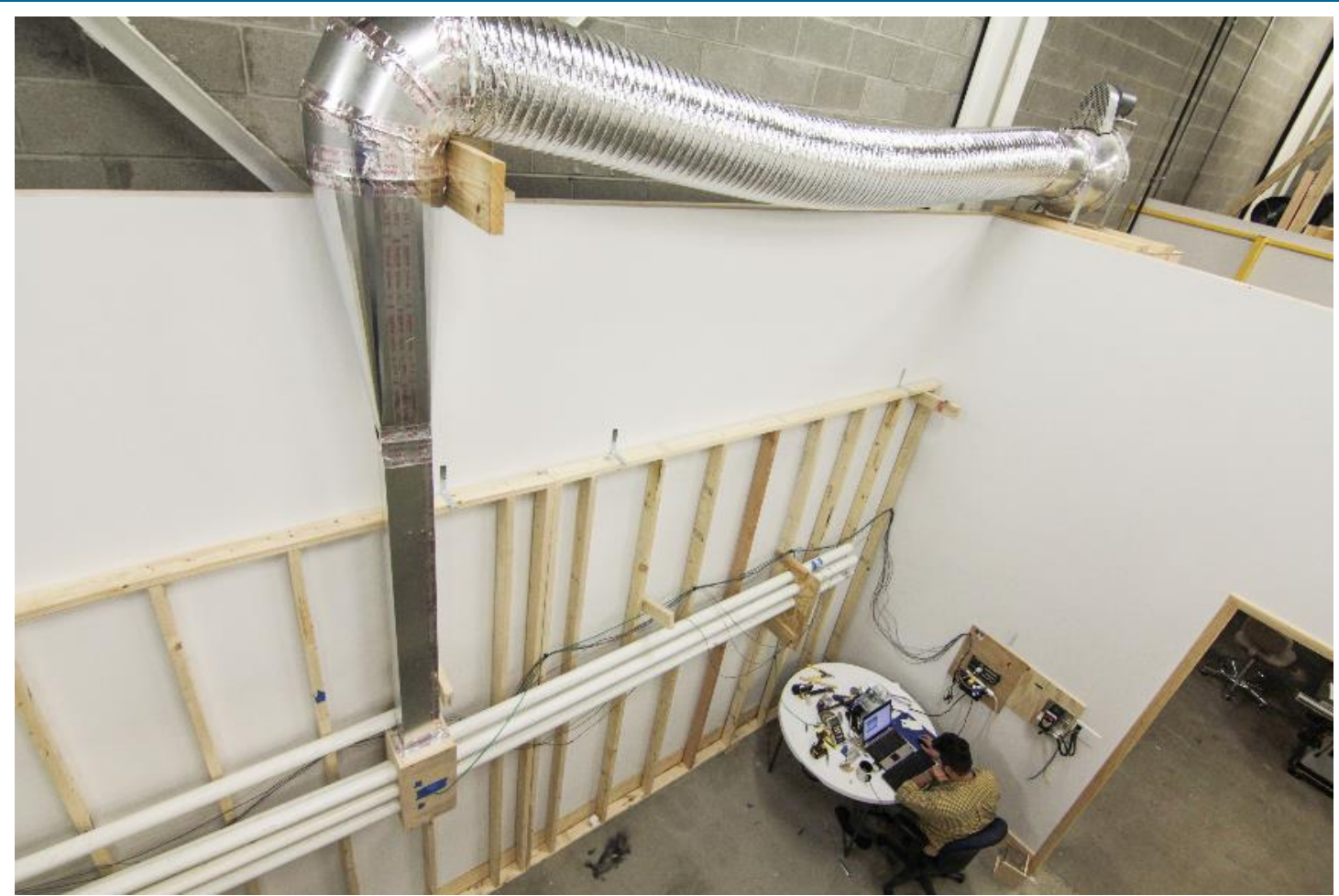

Figure 5. Testing a side outlet manifold configuration

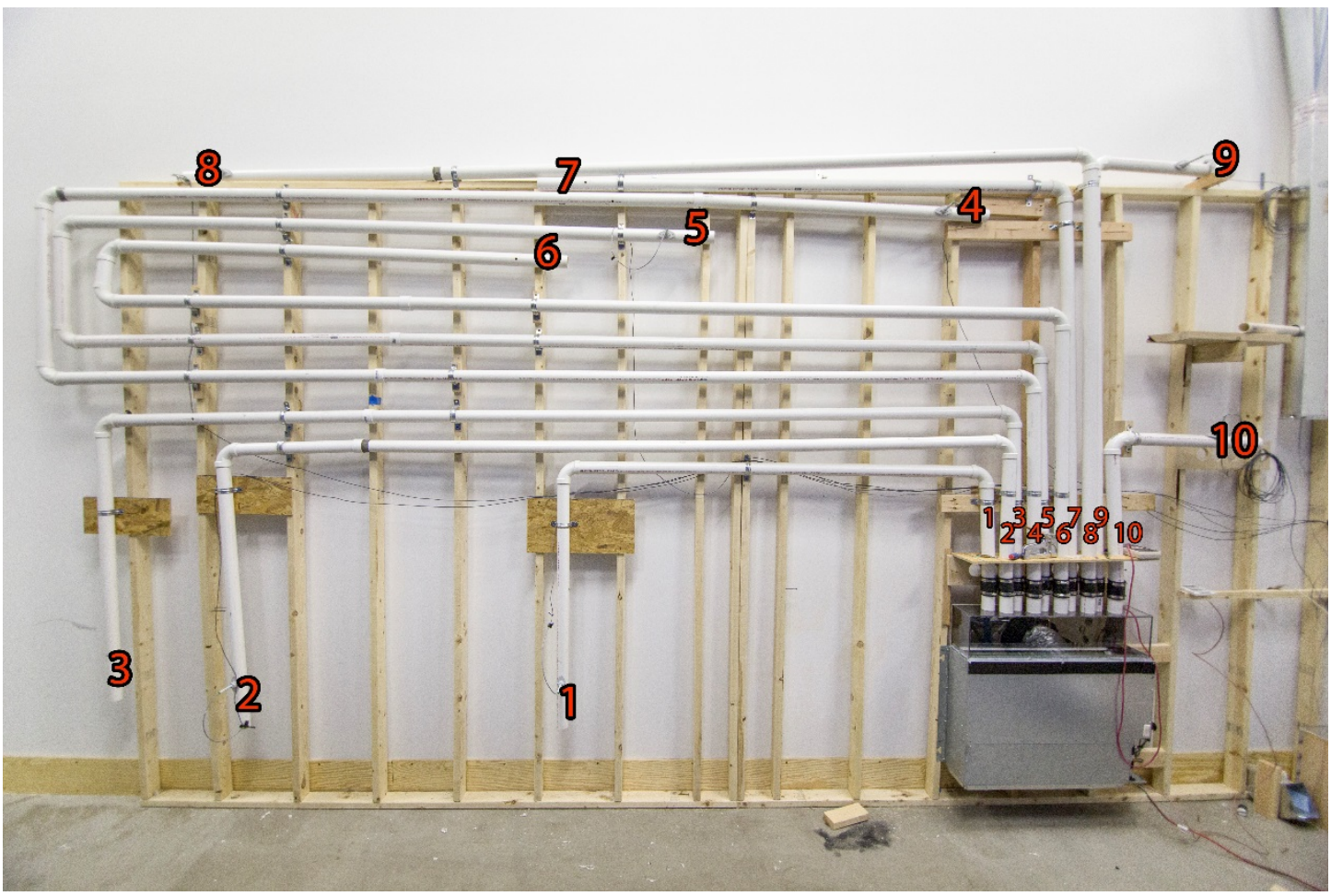

Figure 6. Duct testing mockup for an example case, showing the duct numbers

\subsection{Measurements}

This section describes measurements IBACOS took in the laboratory for this project. 


\subsubsection{Measurement of Differential Pressure}

The research team measured the static pressure (SP) differential from the supply plenum to the ambient room environment and recorded the values for each airflow level and duct configuration tested. These pressure measurements established the pressures against which the air-moving equipment worked in each test case. A project goal was to design systems that minimize the SP to minimize fan energy.

\subsubsection{Measurement of Total System Airflow}

IBACOS sealed the AHUs and plenums so essentially no air leaked from those components. Then the team calculated the total airflow of the system by summing the individual duct airflows. Some cases had too few airflow sensors to have a dedicated sensor in each duct runout. For these cases, the team used the average duct airflow rate to extrapolate the total airflow. This latter approach was used only for the case in which all duct runs were of equal length. As an example of this method, say ten duct runouts and eight sensors were available. If the average reading on each sensor showed 20 CFM, the total system airflow was assumed to be 200 CFM. This assumption may introduce some error if one of the duct runouts that was not sampled had a significantly different airflow.

\subsubsection{Measurement and Calculation of Runout Duct Airflow}

IBACOS used a hot-wire anemometer installed in the center of each duct to measure the air velocity in each small-diameter runout. The probe was installed through the side wall of the duct, with 20 duct diameters straight distance upstream and a minimum of 5 duct diameters downstream of the probe. The team then calculated the volumetric airflow rate by multiplying the area of the duct by the velocity and a correction factor of 0.85 to account for the turbulent velocity profile.

Each velocity sensor had a consistent bias error that was calculated and removed from each sensor reading. Appendix A includes a discussion of this process.

\subsubsection{Airflow Visualization}

The research team used flow visualization to qualitatively analyze the airflow pattern in the plenums and into the small-diameter duct runouts. To do this, the team released theatrical smoke into the center of the supply plenum $18 \mathrm{in}$. before the manifold box. Then the team used a highdefinition video camera to record the smoke as it moved through the clear-top plenum against a flat black background.

\subsubsection{Measurement of Sound Level}

As the air-moving equipment became more loaded against the airflow resistance and as the air velocity increased in the ducts, the sound level increased, as expected. The noise level rating of an air outlet is directly proportional to the air volume supplied through the outlet; the sound increases as more air is supplied. Typically, the noise level of an air outlet is rated with a noise criteria (NC) sound pressure value. The NC level depends on the air volume and neck velocity (Price 2011; AHRI 2008). The NC value assumes a 10-decibel default for average room absorption and an approximate distance of $5 \mathrm{ft}$ from a single source. Large outlets generally are quieter at the same airflow rate than smaller sizes of the same model because of higher free area or lower inlet velocity, or both. Outlets may be selected so the NC level does not exceed the ASHRAE recommended values for the space being considered (ASHRAE 2011). An NC level of 
17 can be considered barely perceptible, whereas an NC level of 37 may be marginally acceptable.

Background noise in the laboratory posed a measurement uncertainty issue that limited detailed comparisons. More accurate sound level testing may be of greater importance when the systems are field applied and are tested in future work.

\subsubsection{Measurement of Air Handling Unit Power}

Power draw of the AHU was measured with a true root-mean-square power meter for only the MSHP mockup configuration. Because of the nature of the experimental setup, measuring the power draw during the tests using the commercial blower would not have been representative of a system as installed in a house. This measurement would be useful for comparing the relative power required for each airflow value; however, the test setup was not identical to the complete set of duct system components used in a real house.

\subsection{Equipment}

Table 2 shows the measurement equipment used for this project.

Table 2. Measurement Equipment Required

\begin{tabular}{c|c}
\hline Measurement & Equipment \\
\hline $\begin{array}{c}\text { Static Pressure Differential from the } \\
\text { Supply Plenum to the Laboratory } \\
\text { Room }\end{array}$ & $\begin{array}{c}\text { Pressure transducer, auto-zeroing, accuracy }< \pm 1.0 \mathrm{~Pa}^{*}, \\
\text { minimum range 0-250 Pa (The Energy Conservatory DG-700) } \\
\text { The Energy Conservatory Duct Blaster system with a digital } \\
\text { pressure gauge as a powered flow hood }\end{array}$ \\
$\begin{array}{c}\text { Airflow of the Total System } \\
\text { Air Velocity/Air Speed in Small- } \\
\text { Diameter Duct Outlets/Runouts }\end{array}$ & $\begin{array}{c}\text { Hot-wire anemometer transducer, accuracy } \pm 5 \% \text { (Elektronik } \\
\text { EE575) }\end{array}$ \\
\hline $\begin{array}{c}\text { Airflow Visualization } \\
\text { Temperature and Relative Humidity } \\
\text { of the Laboratory Room } \\
\text { Sound Level }\end{array}$ & $\begin{array}{c}\text { Theatrical smoke emitter, planar laser (from laser level), high- } \\
\text { resolution video camera }\end{array}$ \\
AHU Power & Standard hygrometer \\
\hline
\end{tabular}

*Pascal 


\section{Results}

This section presents the data from the ten tested duct box designs, followed by the mockup example. Of the ten boxes, the first four were connected to 2-in. ducts; the second four used similar designs and were connected to 2.5 -in. ducts. The final two duct boxes were connected to the ducted MSHP using 2-in. ducts. The boxes were designed as examples that would be easy to fit into interior wall cavities or small bulkheads.

\subsection{Baseline System}

Data collected from the box testing are summarized in this section. The emphasis of this data is to provide an understanding of the airflow distribution across all the individual duct runs. For each tested box, a drawing of the box is shown, followed by four charts. These charts show the percentage deviation of each duct run from the median value airflow rate. As perturbations were made to the duct runout arrangement, the median duct airflow value was held constant from the baseline test so the plots can be compared horizontally. Each perturbation is shown on the same $y$-axis scale as the baseline graphic. Line colors correspond to the outline of the hole in each box. For duct runs with no measurement, the drawing has no colorized line. Whenever a perturbation was made, the line was tripled in weight for identification. Figure 7 shows a rendering of each modification to the duct runout. These plots are shown in Figure 8 through Figure 11. The results from the MSHP duct box are shown in Figure 12. Some of the measurements show random deviation in individual measurements. Box 3 in Figure 9, for example, shows a sudden change in outlet 3 at 100 CFM. This is likely due to recording error and should be disregarded. Appendix B includes data tables that contain the air velocity and flow rate measured from each duct box.
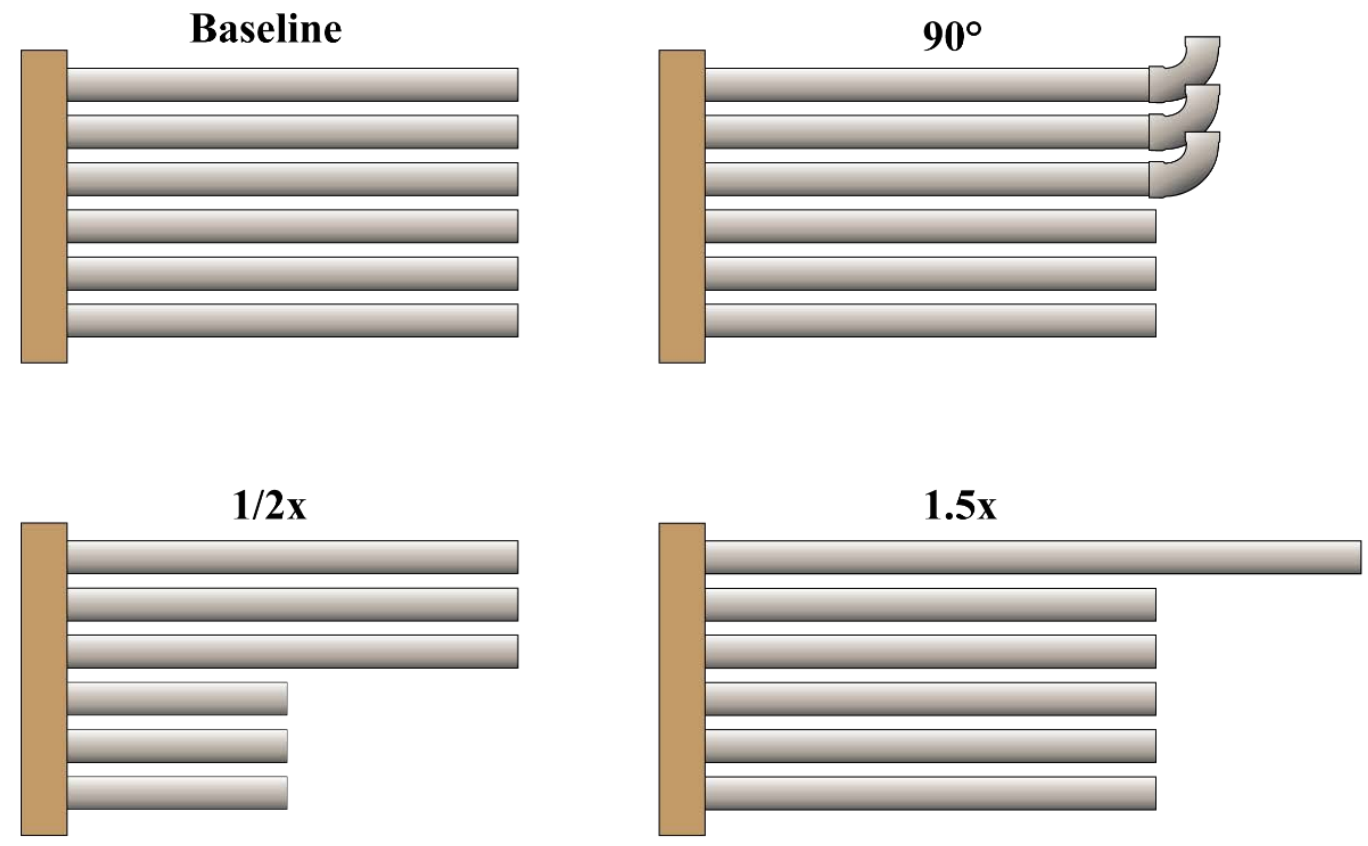

Figure 7. Diagram of duct runout modifications 

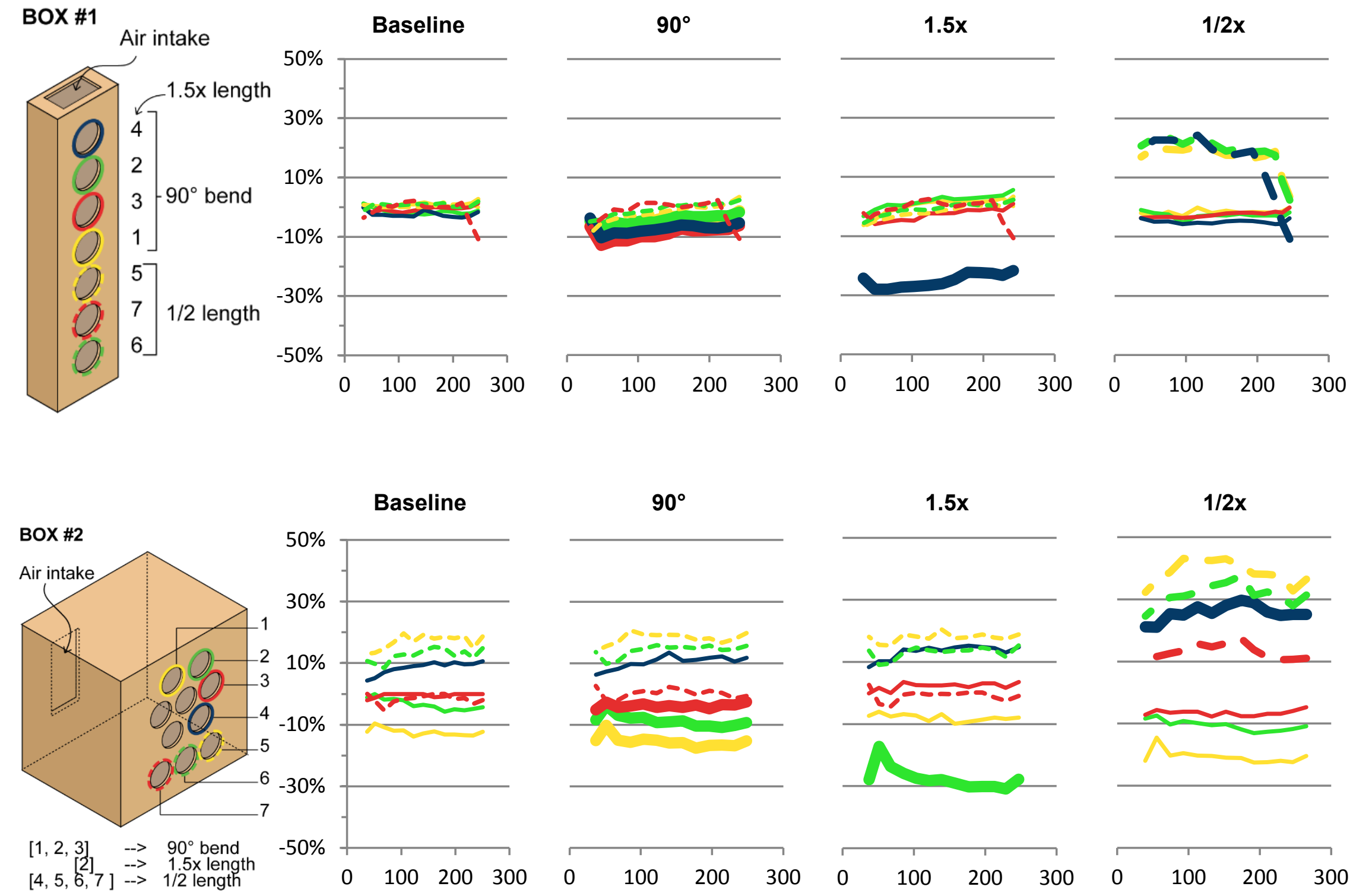

Figure 8. Duct airflow deviation for 2-in. manifold boxes-Box 1 (top) and Box 2 (bottom) 


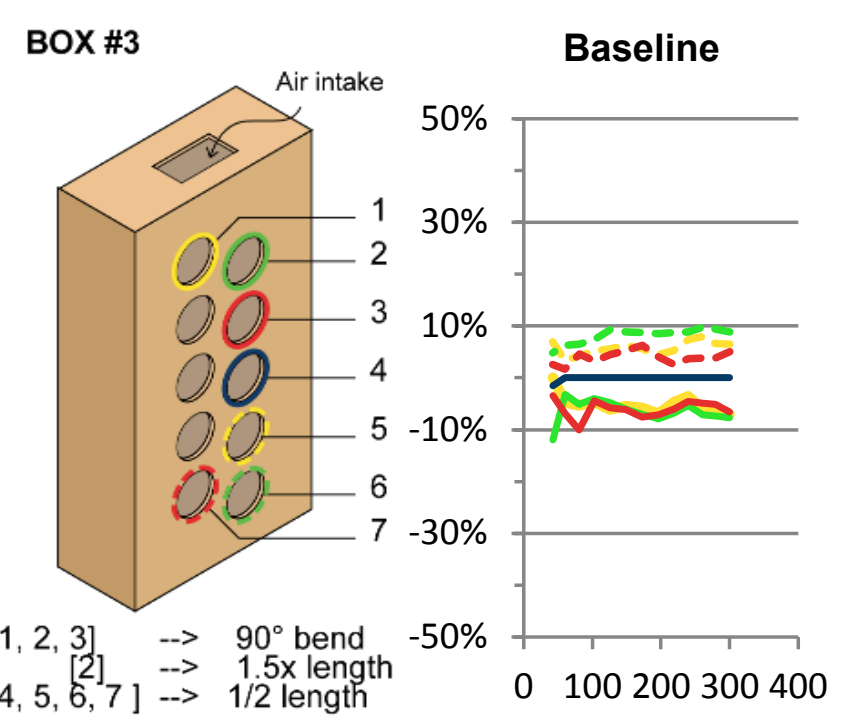

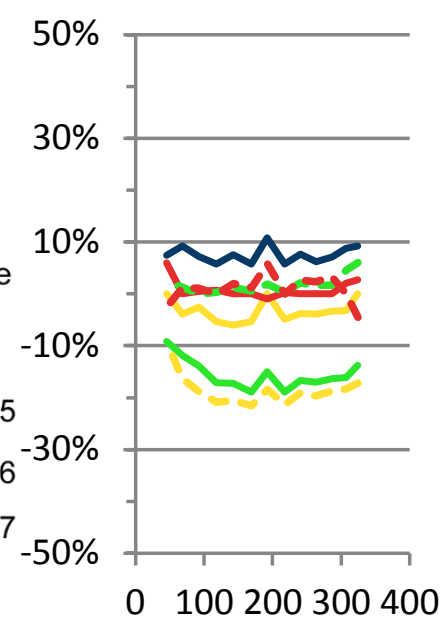

$90^{\circ}$

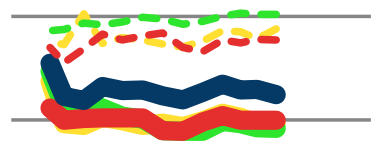

D $100 \quad 200 \quad 300 \quad 400$

$90^{\circ}$

$1.5 x$

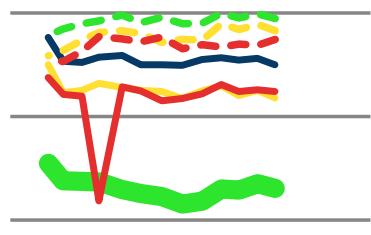

$\begin{array}{lllll}0 & 100 & 200 & 300 & 400\end{array}$

$2 x$

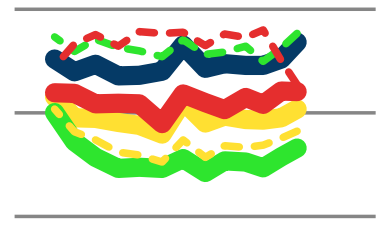

$0 \quad 100200300 \quad 400$
$1 / 2 x$

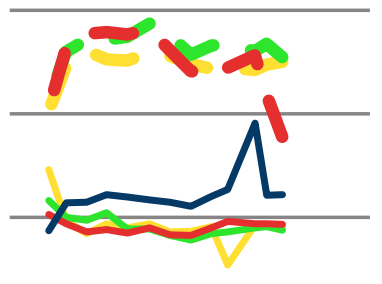

$\begin{array}{lllll}0 & 100 & 200 & 300 & 400\end{array}$

$2 x$

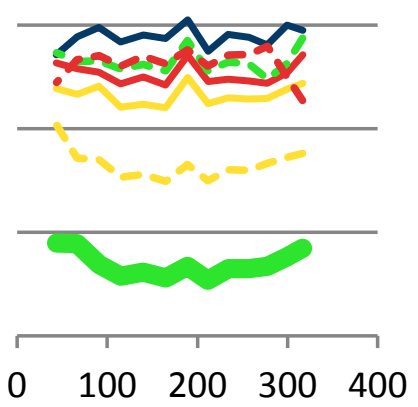

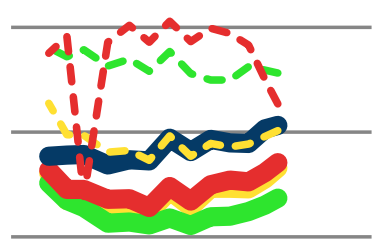

$\begin{array}{lllll}0 & 100 & 200 & 300 & 400\end{array}$

Figure 9. Duct airflow deviation for 2-in. manifold boxes-Box 3 (top) and Box 4 (bottom) 

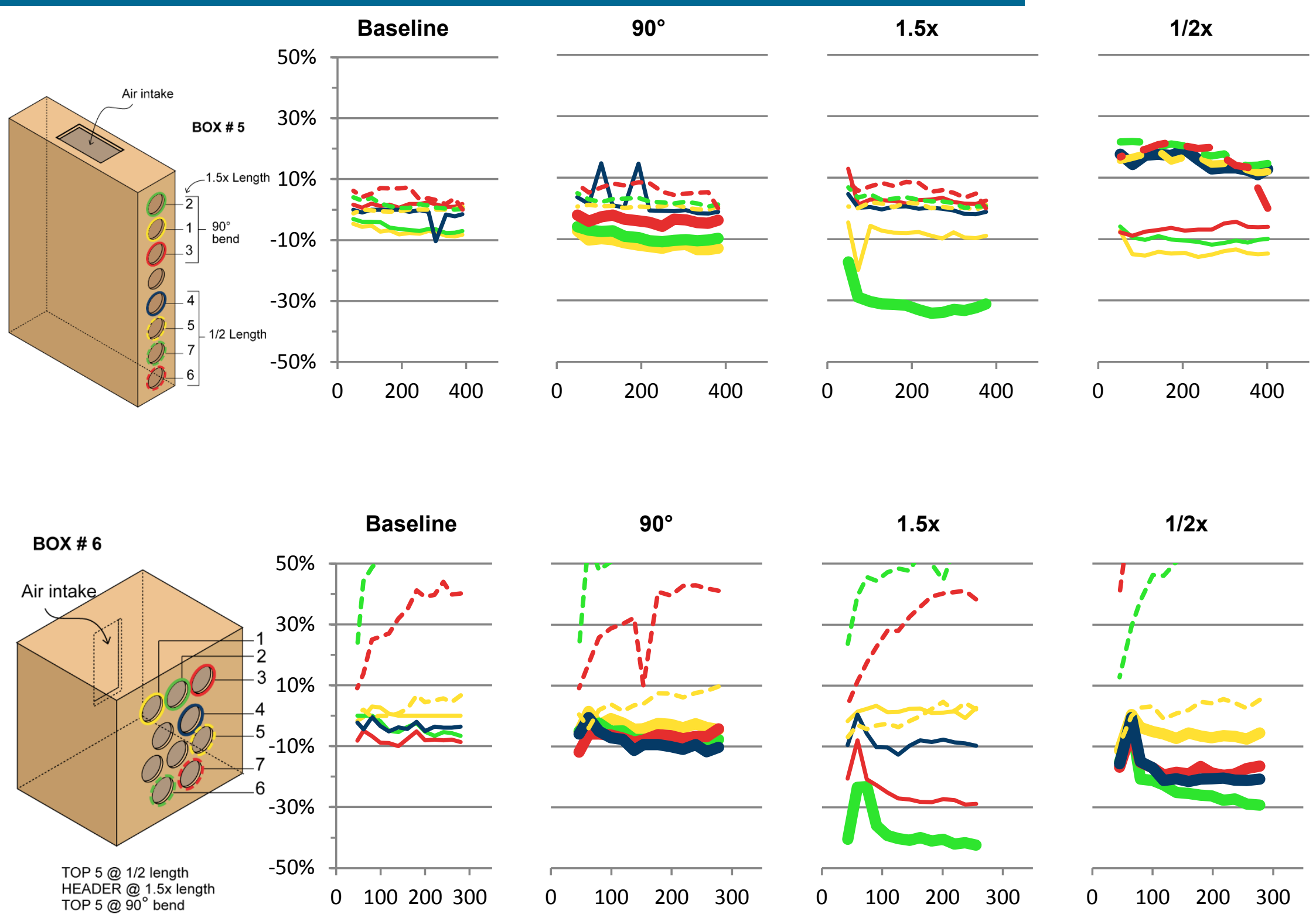

Figure 10. Duct airflow deviation for 2.5-in. manifold boxes-Box 5 (top) and Box 6 (bottom) 


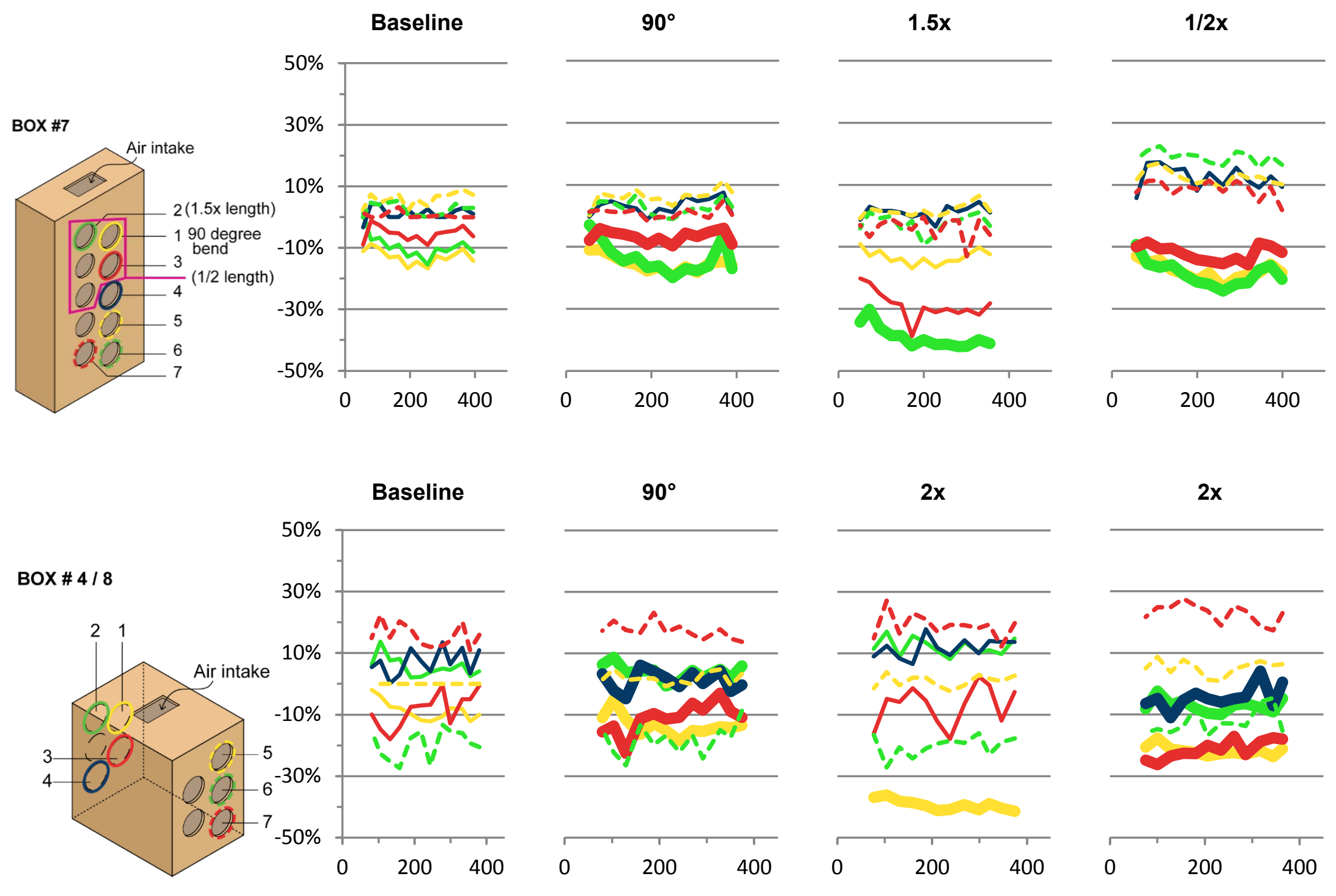

Figure 11. Duct airflow deviation for 2.5-in. manifold boxes-Box 7 (top) and Box 8 (bottom) 

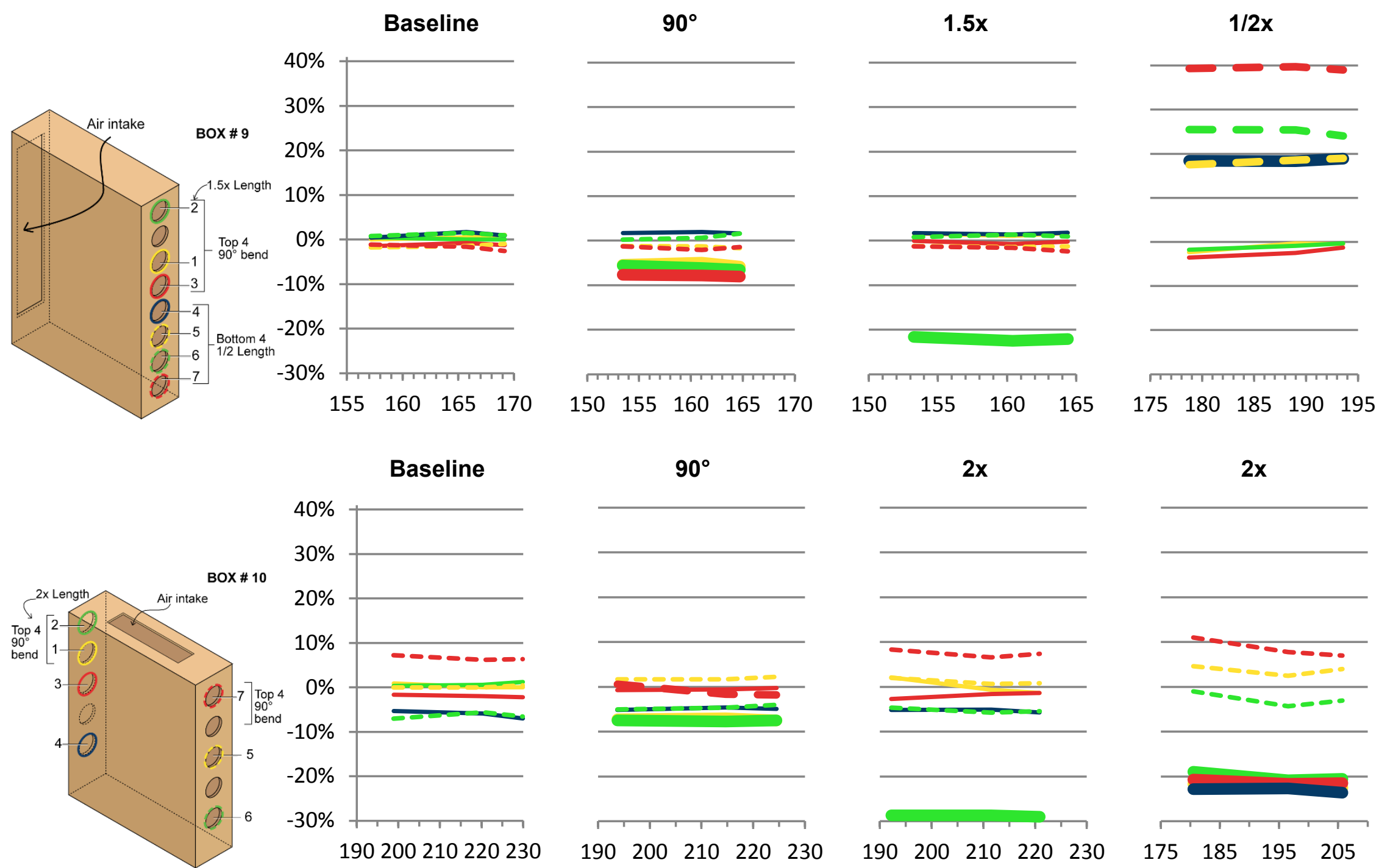

Figure 12. Duct airflow deviation for MSHP manifold boxes-Box 9 (top) and Box 10 (bottom) 


\subsection{As-Installed Example Mockup}

Figure 13 shows the second-floor plan of the sample home used as a basis for the mockup. The ductwork design was such that each run could fit into the required space of the test house. Table 3 shows the results and airflow balance from the example mockup. For reference, the duct numbers listed in the table match the ducts labeled in Figure 6. Figure 14 presents the airflow difference of the mockup duct system relative to duct length.

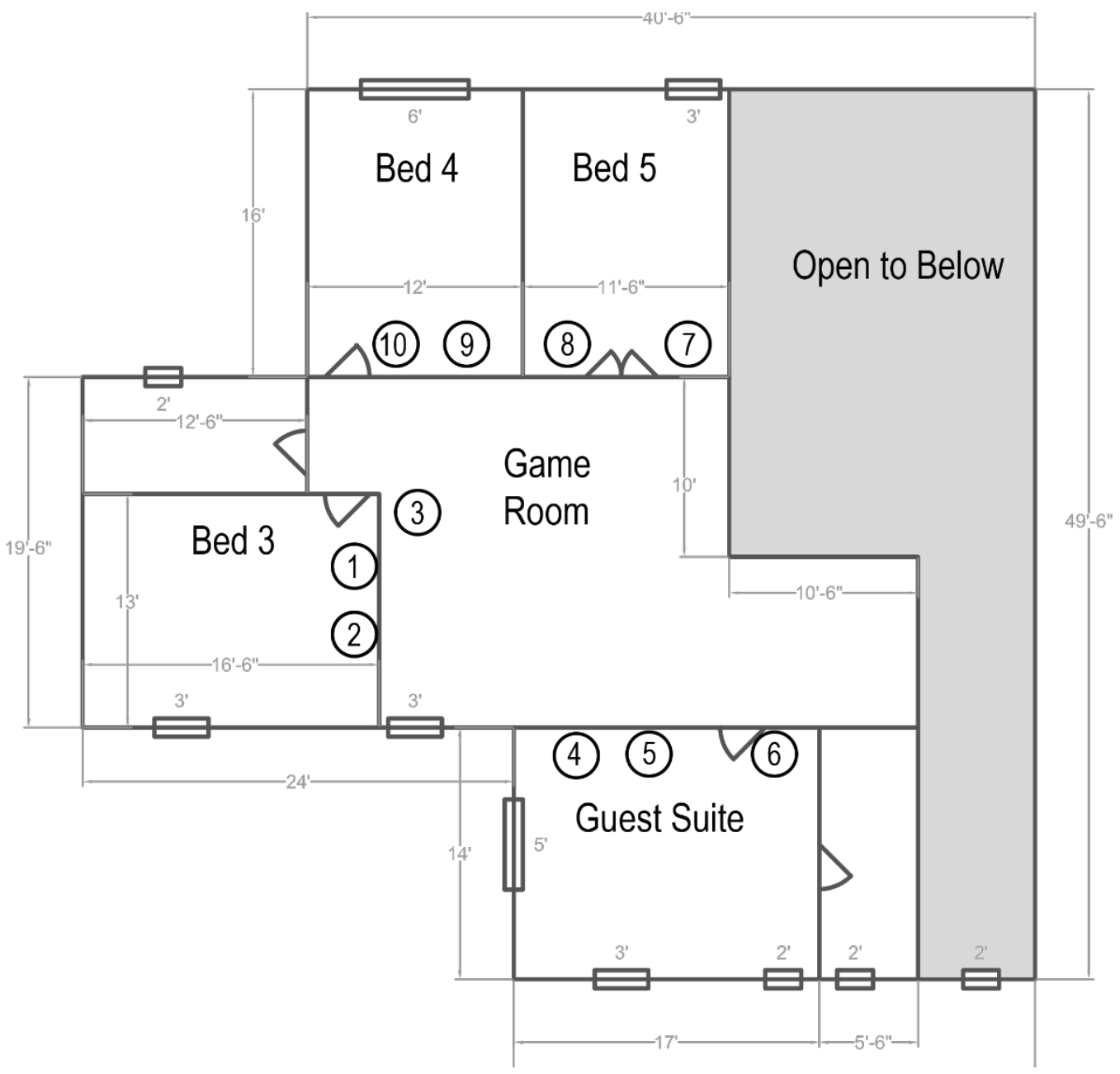

Figure 13. Example house floor plan for mockup (second floor of the home) 
Table 3. Results from the As-Installed Mockup

\begin{tabular}{|c|c|c|c|c|c|}
\hline \multirow[t]{3}{*}{$\begin{array}{c}\text { Duct } \\
\text { Number }\end{array}$} & \multicolumn{3}{|c|}{$\begin{array}{l}\text { Airflow } \\
\text { (CFM) }\end{array}$} & $\begin{array}{c}\text { Length } \\
\text { (ft) }\end{array}$ & $\begin{array}{l}\text { Number of } \\
\text { Bends }\end{array}$ \\
\hline & \multicolumn{3}{|c|}{ Fan Speed } & & \\
\hline & Low & Medium & High & & \\
\hline 1 & 17 & 19 & 19 & 12.7 & 2 \\
\hline 2 & 15 & 16 & 16 & 19.1 & 2 \\
\hline 3 & 15 & 16 & 16 & 21.58 & 2 \\
\hline 4 & 12 & 13 & 14 & 36.41 & 3 \\
\hline 5 & 13 & 15 & 15 & 31.02 & 3 \\
\hline 6 & 14 & 15 & 15 & 27.45 & 3 \\
\hline 7 & 18 & 20 & 20 & 14.7 & 1 \\
\hline 8 & 16 & 17 & 18 & 21.2 & 1 \\
\hline 9 & 18 & 19 & 20 & 9 & 1 \\
\hline 10 & 21 & 23 & 24 & 5.1 & 1 \\
\hline Power (Watts) & 26.3 & 32.6 & 39.2 & & \\
\hline Total CFM & 160 & 172 & 176 & & \\
\hline Watt/CFM & 0.16 & 0.19 & 0.22 & & \\
\hline Static Pressure $(\mathbf{P a})$ & 43.0 & 48.4 & 51.5 & & \\
\hline
\end{tabular}

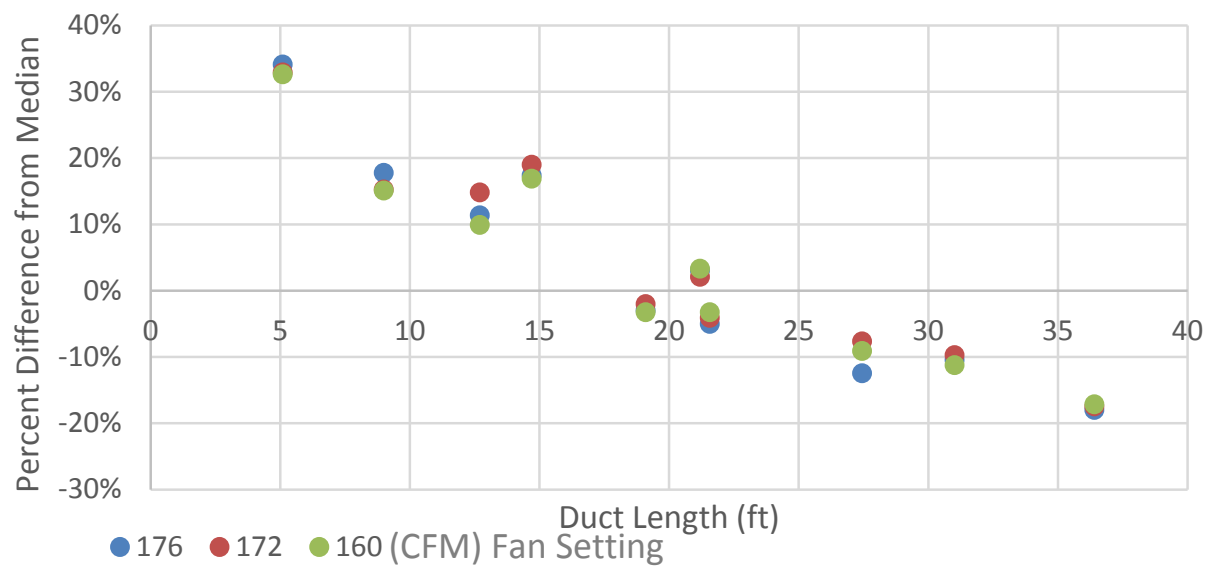

Figure 14. Airflow deviation of the mockup duct system relative to duct length

The key measure of success for the example mockup is the ability of the duct system to meet the sample home's calculated heating and cooling loads from ACCA Manual J (Rutkowski 2006). Equation 3 and Equation 4 were used to calculate delivered energy. Heating mode assumed only sensible energy change through the coil with a $50^{\circ} \mathrm{F}$ temperature rise. Cooling mode assumed a $25^{\circ} \mathrm{F}$ temperature reduction and 22 grains of water removed per pound of dry air. Figure 15 shows the delivered energy of the example system compared to the calculated loads. 


$$
\begin{aligned}
& \text { Sensible Heat }\left(\frac{B t u}{h}\right)=C F M * 1.1 * \Delta T\left({ }^{\circ} \mathrm{F}\right) \\
& \text { Latent Heat }\left(\frac{B t u}{h}\right)=C F M * 0.69 * \Delta \chi\left(\frac{\text { grains }}{\mathrm{lb}}\right)
\end{aligned}
$$

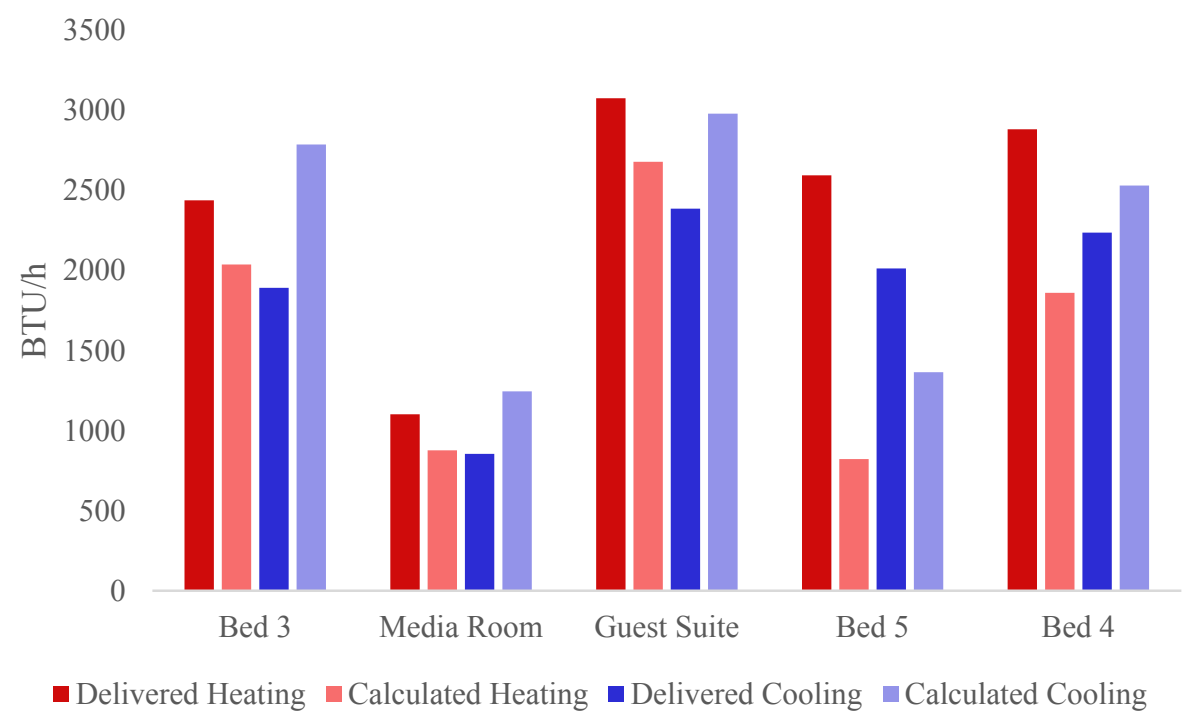

Figure 15. Example system delivered energy

Once the team measured the airflow for which the MSHP blower was capable, additional measurements were taken with a Duct Blaster boost fan in series to increase the SP and flow rate. Figure 16 presents the resulting duct curve along with the AHU manufacturer-supplied airflow rate versus SP curves. The intersection of these curves represents possible system operation points. 


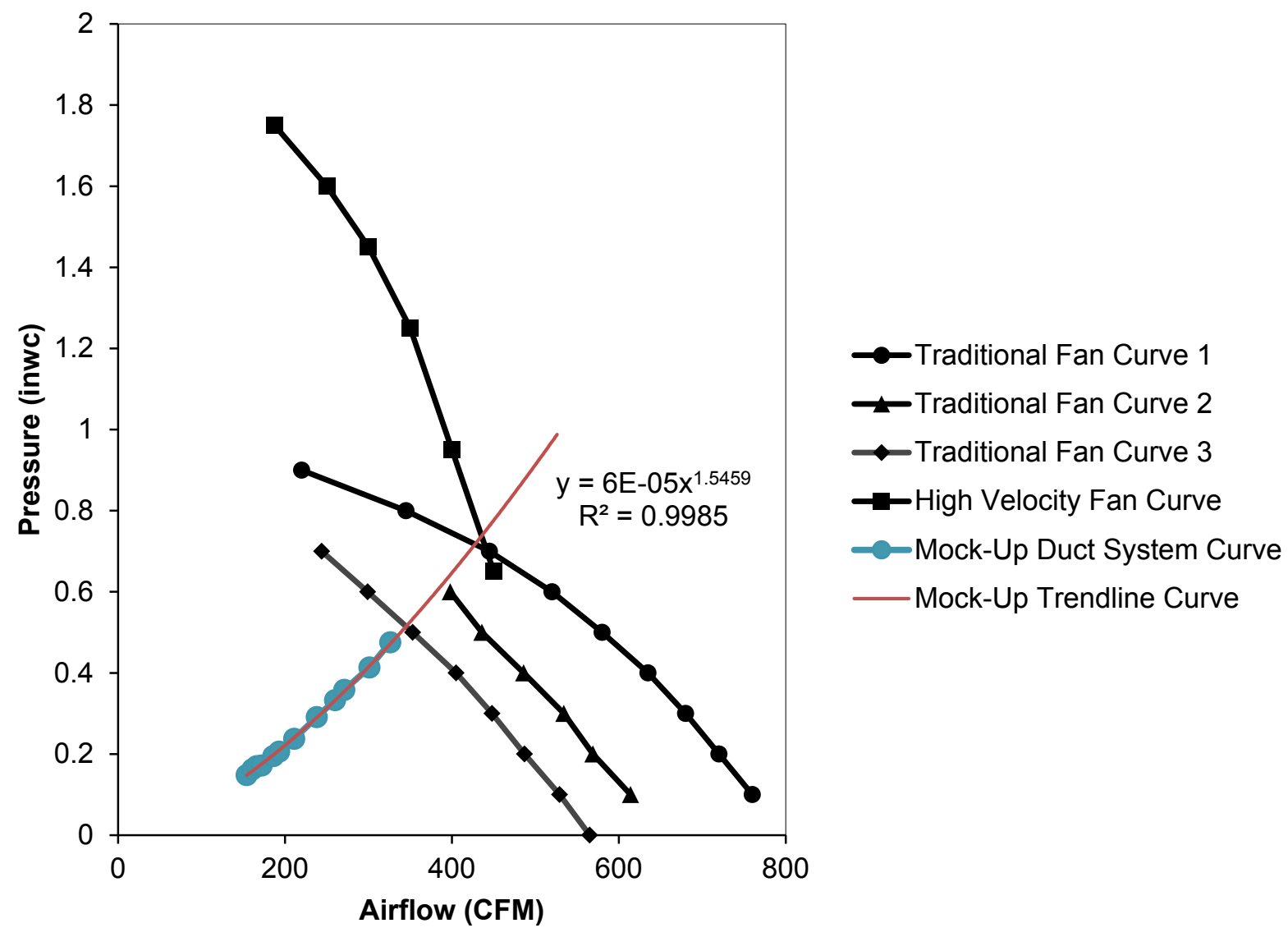

Figure 16. Measured duct pressure versus airflow relationship and common fan curves

Data collected when the Duct Blaster was used as a boost fan are presented in Table 4. These data are included to provide an idea of possible flow rates given a more powerful MSHP fan. The first three test measurements used standard Duct Blaster airflow measurement techniques to target zero external SP in the return plenum. The second three tests aimed to recreate the supply plenum pressure measured with only the MSHP fan connected. Finally, the Duct Blaster was ramped up to determine the SP needed for additional airflow through the duct system. As the SP was boosted, the team noticed significant air leaking from the MSHP cowling. A subsequent test of the duct leakage revealed that when the outlet of each duct was sealed with duct mask, total leakage at 24 Pascals (Pa) was 20 CFM. The team then sealed the MSHP cowling with duct mask and retested the duct leakage to find it had reduced to $11 \mathrm{CFM}$. These results led the team to believe significant leakage had occurred through the MSHP cowling, which is evident when the Duct Blaster measured cubic feet per minute is compared with the total system airflow calculated in Table 3 (166 versus 176 CFM). Taking this leakage into consideration, the method of calculating total system airflow by summing the individual duct airflow rates provides an accurate number. 
Table 4. Manifold and Duct System Flow Measurement

\begin{tabular}{|c|c|c|c|c|c|c|}
\hline $\begin{array}{l}\text { Duct } \\
\text { Blaster } \\
\text { Ring }\end{array}$ & $\begin{array}{l}\text { MSHP } \\
\text { Fan } \\
\text { Setting }\end{array}$ & $\begin{array}{l}\text { Supply } \\
\text { SP } \\
\text { (Pa) }\end{array}$ & $\begin{array}{l}\text { Duct } \\
\text { Blaster } \\
\text { (CFM) }\end{array}$ & $\begin{array}{l}\text { Return } \\
\text { SP } \\
\text { (Pa) }\end{array}$ & $\begin{array}{l}\text { MSHP } \\
\text { Power } \\
\text { (W) }\end{array}$ & \\
\hline 2 & 1 & 37 & 154 & 0 & 28.8 & \multirow{3}{*}{$\begin{array}{c}\text { Aiming for } 0 \text { Duct Blaster } \\
\text { SP }\end{array}$} \\
\hline 2 & 2 & 40.6 & 161 & 0 & 34.9 & \\
\hline 2 & 3 & 42.5 & 166 & 0 & 41.9 & \\
\hline 2 & 1 & 43 & 172 & 10.4 & 29.1 & \multirow{3}{*}{$\begin{array}{l}\text { Aiming for same plenum } \\
\text { SP as test without the } \\
\text { Duct Blaster }\end{array}$} \\
\hline 2 & 2 & 48.7 & 186 & 13.8 & 35.4 & \\
\hline 2 & 3 & 51.5 & 193 & 14.4 & 42.2 & \\
\hline 2 & 3 & 59.4 & 211 & 26.2 & 42.6 & \multirow{6}{*}{$\begin{array}{c}\text { Using a Duct Blaster as a } \\
\text { boost fan to push beyond } \\
\text { AHU flow }\end{array}$} \\
\hline 2 & 3 & 72.8 & 238 & 46.4 & 43.1 & \\
\hline 2 & 3 & 83.2 & 260 & 63.5 & 43.6 & \\
\hline 1 & 3 & 89.6 & 271 & 72 & 44.0 & \\
\hline 1 & 3 & 103.4 & 301 & 95.2 & 44.1 & \\
\hline 1 & 3 & 118.9 & 326 & 121.8 & 44.5 & \\
\hline
\end{tabular}

\subsection{Measured Results and Air Conditioning Contractors of America Manual D}

The MSHP mockup layout used multiple $90^{\circ}$ fittings in the design. Because pressure drop through the small-diameter duct system can be significant, the research team calculated the pressure drop of the system using values provided in ACCA Manual D (Appendix 3, Group 8 Elbows and Offsets) (Rutkowski 2009). The analysis revealed a difference between some of the measured pressure drops associated with $90^{\circ}$ elbows and the ACCA-specified pressure drop. Specifically, ACCA Manual D indicates that for a radius/diameter ratio of 1.0 of a smooth elbow, the equivalent length is $15 \mathrm{ft}$ per $90^{\circ}$ elbow; the empirical measurements indicated that the equivalent length of the fitting was $5 \mathrm{ft}$. To further investigate this discrepancy, the team used a Duct Blaster to provide airflow and used a manometer to measure the pressure drop due to a 2in.-diameter $90^{\circ} \mathrm{PVC}$ elbow. A number of configurations were evaluated (Table 5). For reference, a close-up of the elbows used in testing is presented in Figure 17. 


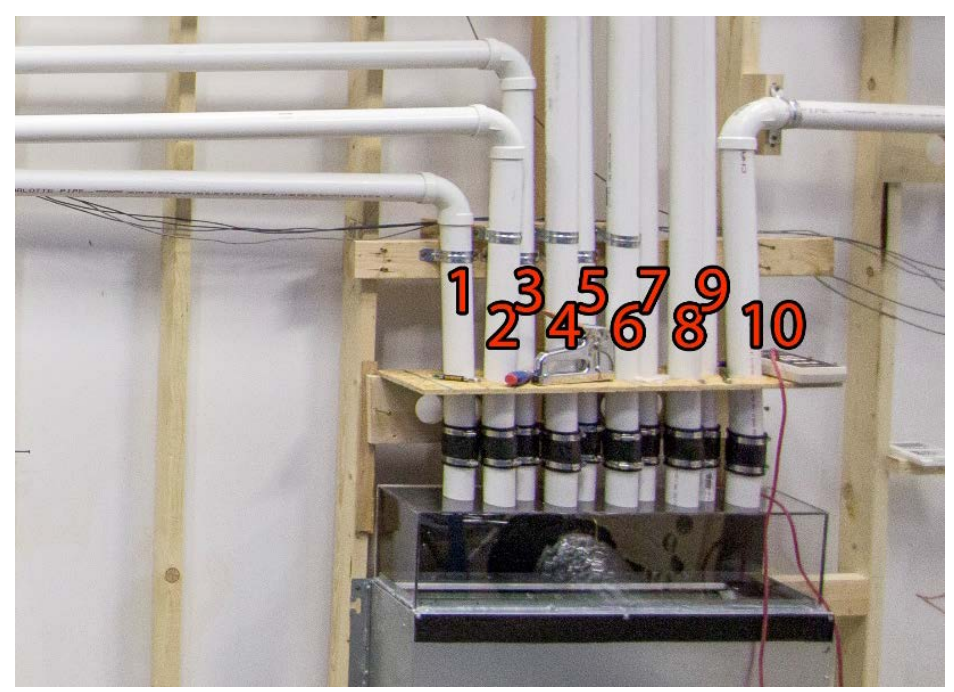

Figure 17. Mockup duct system showing elbows

Table 5. Measured Results

\begin{tabular}{|c|c|c|c|c|c|c|c|}
\hline \multirow{3}{*}{$\begin{array}{c}\begin{array}{c}\text { Number } \\
\text { of }\end{array} \\
10-\mathrm{Ft} \\
\text { Sections }\end{array}$} & \multirow{2}{*}{$\begin{array}{c}\text { Number } \\
\text { of } \\
\text { Elbows }\end{array}$} & \multicolumn{6}{|c|}{$\begin{array}{c}\text { Pressure Drop } \\
(\mathrm{Pa}) \text { [in. water column] }\end{array}$} \\
\hline & & & & & & & \\
\hline & & 10 CFM & 15 CFM & 20 CFM & 25 CFM & 30 CFM & 40 CFM \\
\hline $\mathbf{0}$ & 1 & $3.9[0.02]$ & $7.4[0.03]$ & $11.4[0.05]$ & 16.9 [0.07] & $23.3[0.09]$ & $37.9[0.15]$ \\
\hline 1 & 0 & 8.7 [0.03] & $17[0.07]$ & $27.3[0.11]$ & $39.5[0.16]$ & $53[0.21]$ & $86.4[0.35]$ \\
\hline 2 & 0 & $14.1[0.06]$ & $28.3[0.11]$ & $45.8[0.18]$ & $68.2[0.27]$ & $90.2[0.36]$ & $145.3[0.58]$ \\
\hline 2 & 1 & $16.1[0.06]$ & $31.7[0.13]$ & $50.1[0.20]$ & $74.4[0.30]$ & $101.3[0.41]$ & $158.9[0.64]$ \\
\hline 2 & 2 & $18.7[0.08]$ & $36[0.14]$ & $58.8[0.24]$ & $80.5[0.32]$ & $115.7[0.46]$ & $178.3[0.72]$ \\
\hline
\end{tabular}

The team used the results shown in Table 5 to determine the equivalent length of the $90^{\circ}$ elbow. The results indicate that the equivalent length of a $90^{\circ}$ elbow is $4 \mathrm{ft}$, based on the equivalent pressure drop of straight duct. This is $73 \%$ lower than the data provided in ACCA Manual D (Rutkowski 2009). The reason for the significant difference between the ACCA values and the measured data is ACCA's higher friction rate assumption for the duct material.

\subsection{Airflow Visualization}

The flow visualizations shown in Figure 18 are from the test case with all side outlets similar to those of Box 1. Still images extracted from video clips at $1 \mathrm{~s}$ and $4 \mathrm{~s}$ from injecting a 1-s pulse of smoke into the supply plenum $12 \mathrm{in}$. before the plenum box are shown. Images from higher airflow rates than those presented were too obscured to be usable because of the high velocity of the smoke front. A brighter laser would have allowed for faster shutter speeds and the capture of higher airflow rates. The camera and lens setup was ISO 5000, 0.01-s shutter speed, 85 -mm focal length, and $\mathrm{f} / 1.2$ aperture. 


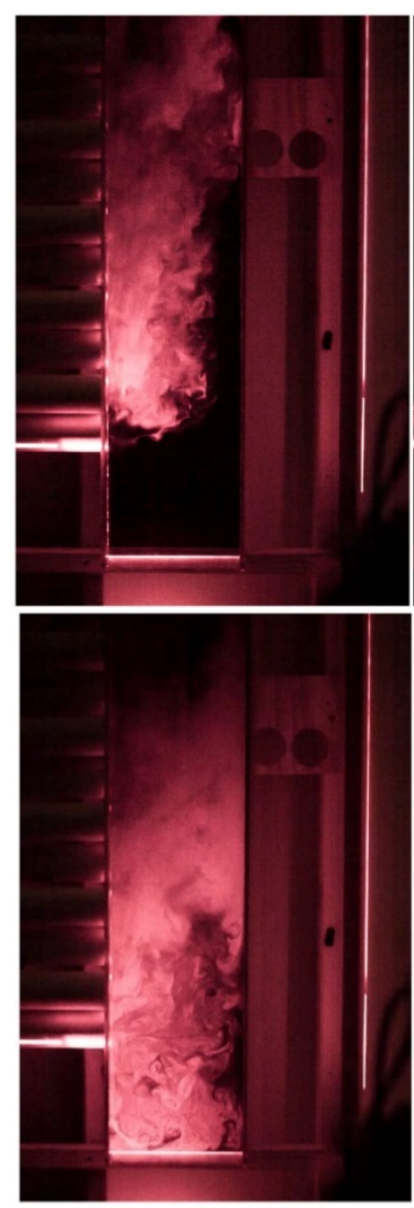

$40 \mathrm{CFM}$

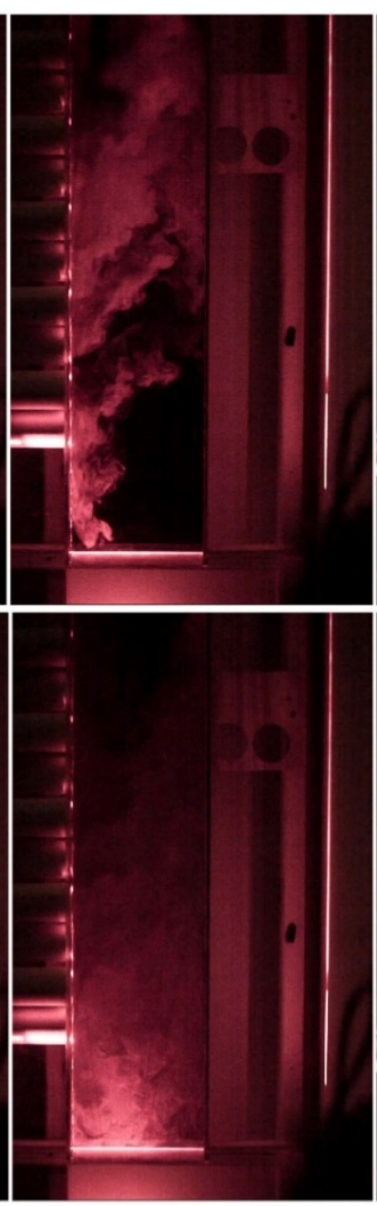

60 CFM

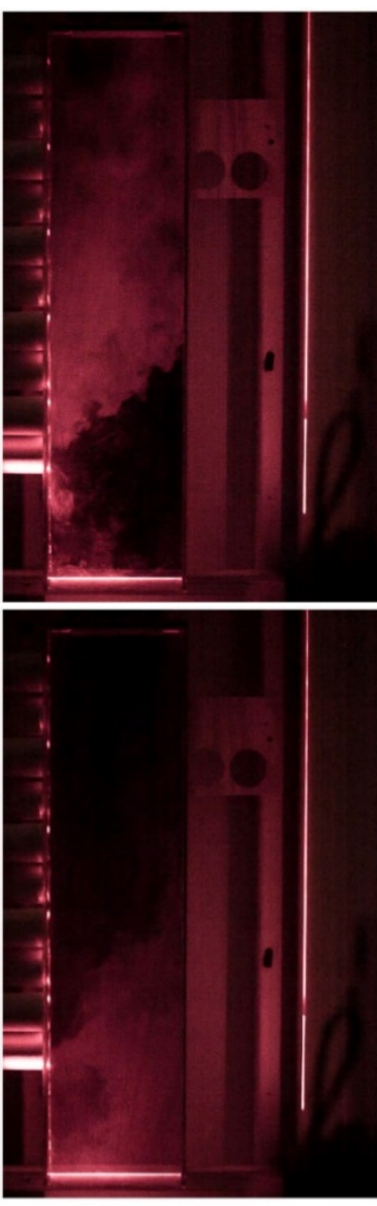

80 CFM

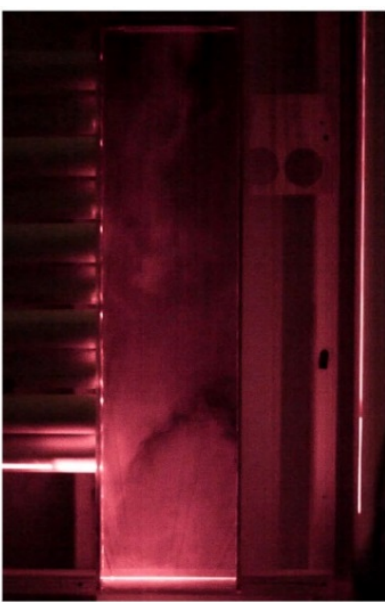

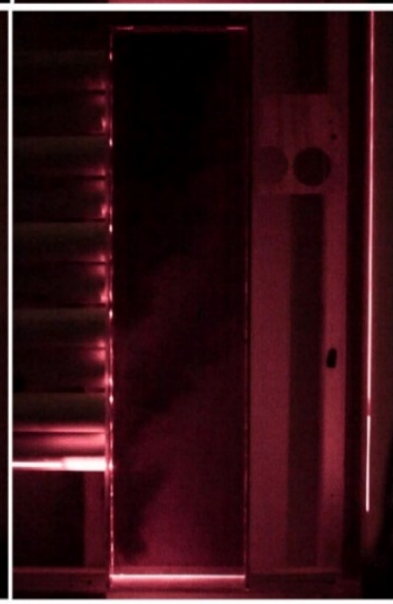

125 CFM

Figure 18. Flow in top-down configuration after $1 \mathrm{~s}$ (top series) and $4 \mathrm{~s}$ (bottom series)

Video footage shows a tendency for the airflow to form a rotational vortex in the bottom of the box. A better box design would include a taper toward the bottom of the box to accommodate the loss in air pressure.

In addition to visualizing the airflow inside the plenum box, the team used a similar setup to image the airflow leaving the duct. For this test, the team connected a Duct Blaster to a single 10 -ft section of 2-in.-diameter pipe and supplied a constant 20 CFM of air through the pipe. Theatrical smoke was introduced near the inlet of the Duct Blaster. A horizontal planar laser was shone through the smoke from a vantage point immediately above and parallel with the duct outlet. Video footage was captured from a vantage point $12.5 \mathrm{ft}$ below the duct outlet. Figure 19 represents a single frame taken from the video footage several seconds after the smoke was introduced, when the shape of the smoke had taken a steady state. The luminance value was inverted for ease of viewing the image.

A qualitative analysis of the throw indicates the throw reaches nearly $10 \mathrm{ft}$ from the outlet. Poerschke (2015) provided further discussion about throw from small-diameter duct systems. 


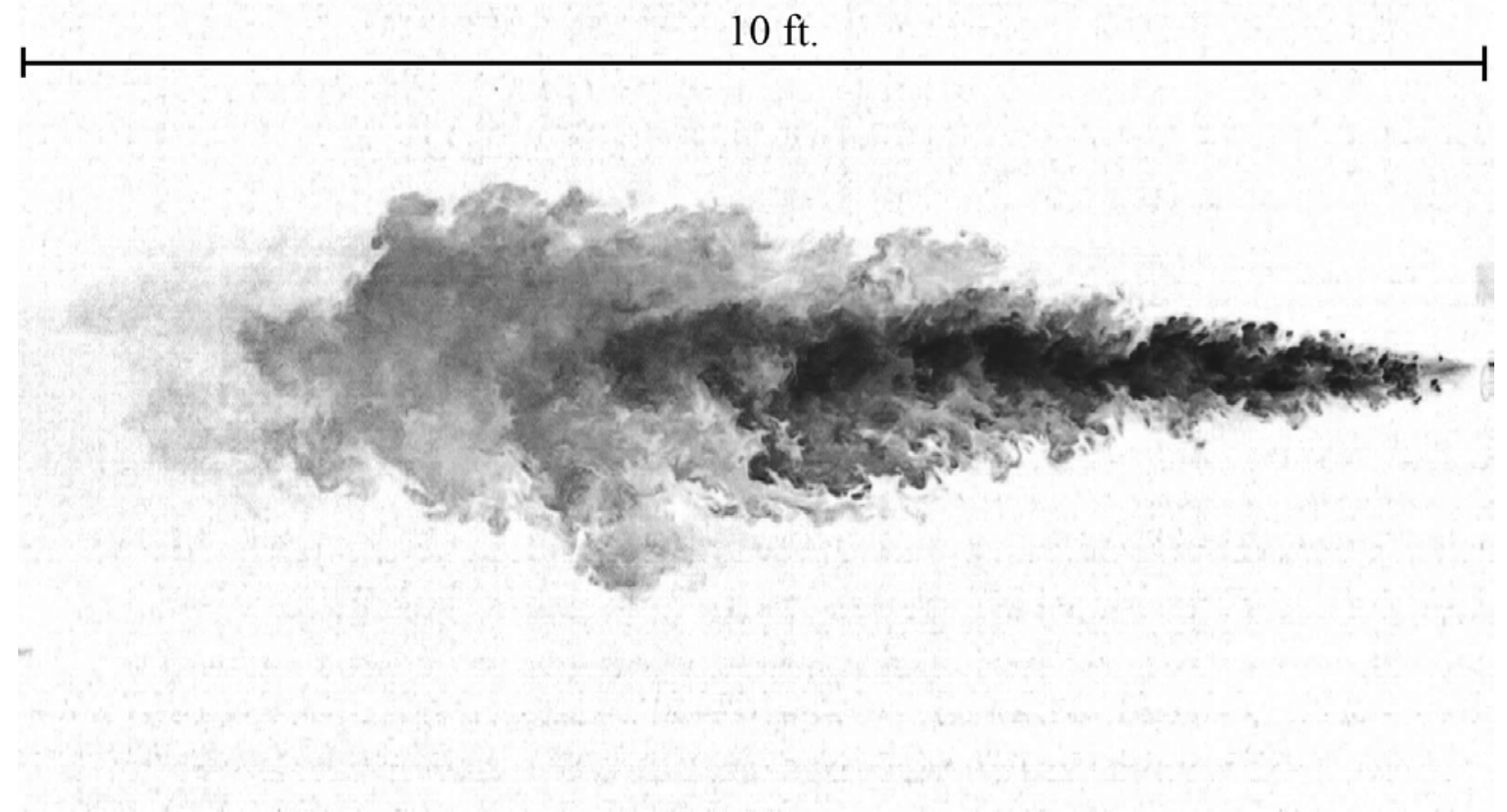

Figure 19. Airflow exiting a 2-in. smooth outlet (20 CFM)

The results of the duct box testing are summarized in Table 6. "Min. Flow" represents the minimum total system airflow rate tested. "Max. Flow" represents the maximum tested airflow rate. The "Median Port" is the plenum outlet that had the statistical median airflow. These values are presented for the lowest "low flow" and the highest "high flow" tested. 
Table 6. Summary of Plenum Box Testing Results

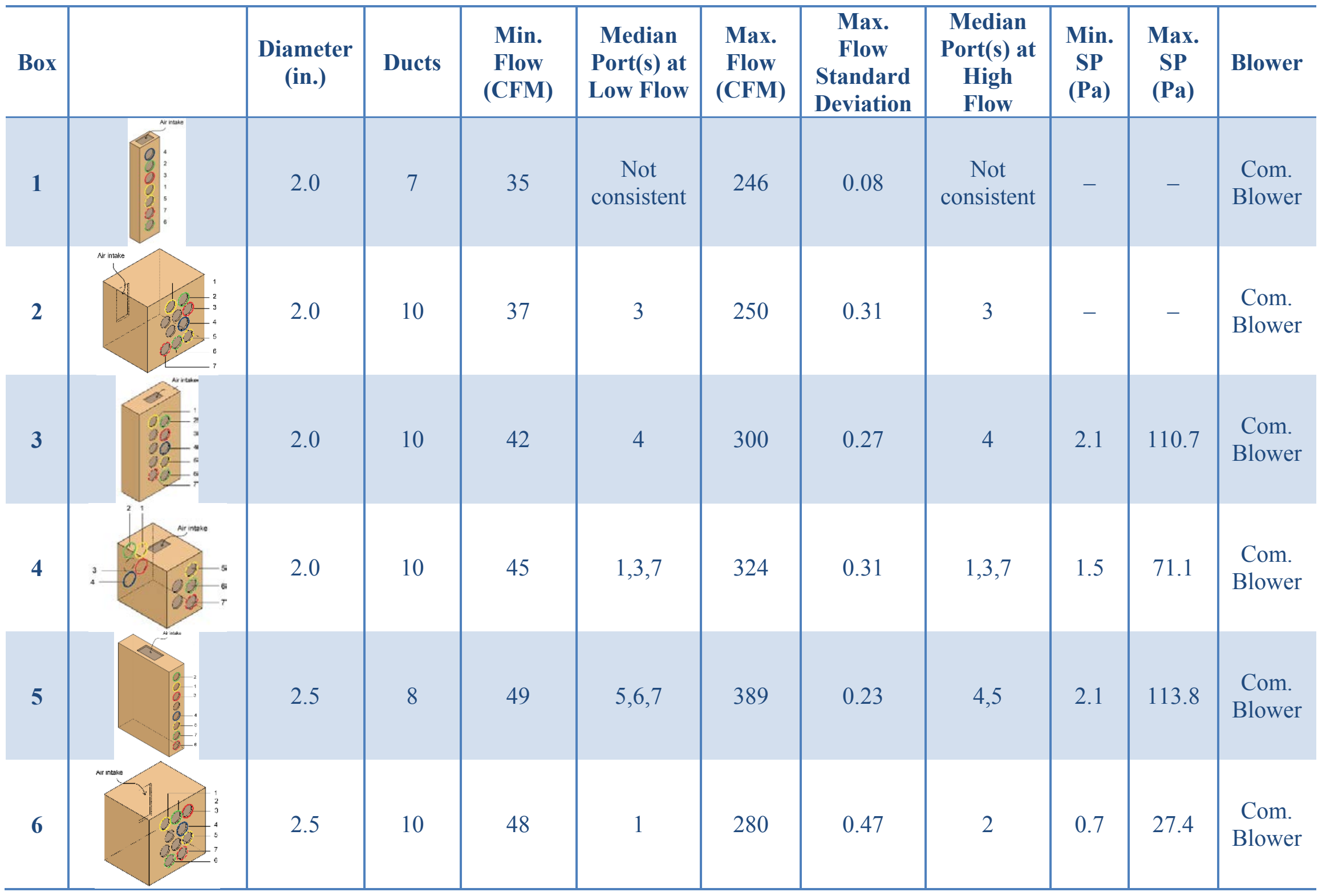




\begin{tabular}{|c|c|c|c|c|c|c|c|c|c|c|}
\hline Box & $\begin{array}{l}\text { Diameter } \\
\text { (in.) }\end{array}$ & Ducts & $\begin{array}{l}\text { Min. } \\
\text { Flow } \\
\text { (CFM) }\end{array}$ & $\begin{array}{l}\text { Median } \\
\text { Port(s) at } \\
\text { Low Flow }\end{array}$ & $\begin{array}{l}\text { Max. } \\
\text { Flow } \\
\text { (CFM) }\end{array}$ & $\begin{array}{c}\text { Max. } \\
\text { Flow } \\
\text { Standard } \\
\text { Deviation }\end{array}$ & $\begin{array}{c}\text { Median } \\
\text { Port(s) at } \\
\text { High } \\
\text { Flow } \\
\end{array}$ & $\begin{array}{l}\text { Min. } \\
\text { SP } \\
\text { (Pa) }\end{array}$ & $\begin{array}{l}\text { Max. } \\
\text { SP } \\
(\mathbf{P a})\end{array}$ & Blower \\
\hline 7 & 2.5 & 10 & 55 & 4,7 & 395 & 0.30 & $4,6,7$ & 1.4 & 70.2 & $\begin{array}{l}\text { Com. } \\
\text { Blower }\end{array}$ \\
\hline 8 & 2.5 & 10 & 54 & 5 & 380 & 0.47 & 5 & 0.7 & 24.3 & $\begin{array}{l}\text { Com. } \\
\text { Blower }\end{array}$ \\
\hline 9 & 2.0 & 8 & 157 & 1,2 & 169 & 0.29 & 1,2 & - & - & MSHP \\
\hline 10 & 2.0 & 10 & 199 & 1,5 & 230 & 1.10 & 1,5 & 20.2 & 23.2 & MSHP \\
\hline 11 & 2.0 & 10 & 160 & 2,8 & 180 & 3.20 & 2,5 & 43.0 & 51.5 & $\begin{array}{l}\text { MSHP } \\
+ \text { Duct } \\
\text { Blaster }\end{array}$ \\
\hline
\end{tabular}




\section{Discussion}

Several features describe the most successful box geometries. Initially, some plenum boxes showed excellent balance; all duct runs had equal length.

Each duct box showed some unique behavior because of geometry and hole location. The tall and narrow Box 1 and Box 5 both showed relatively equal exiting airflow; the bottom outlets received slightly more airflow than the top outlets.

Box 2 and Box 6 showed the least uniform behavior because of the relatively small inlet aimed directly at a few outlets. In this case, the bottom outlets also were favored because of the inlet design. Airflow was coming from above the box, into a $90^{\circ}$ elbow, with little distance to straighten the flow. This caused pressure to build in the bottom of the box and thus greater airflow out of the bottom-most outlets. A better design for this box would incorporate a flowdiffusing device into the box but at the expense of creating more SP. The box design showing the most uniform baseline airflow, Box 9, had an inlet geometry that closely matched the layout of the outlet holes.

Box 4 and Box 8 showed a preference for the bottom outlets receiving more airflow; adding a $90^{\circ}$ elbow at the end of some outlets had a small but noticeable impact on the outlet airflow. Typically, a reduction in airflow of $5 \%$ or less was measured. This is to be expected with such a small restriction added.

Increasing one duct length by a factor of 1.5 resulted in a roughly $30 \%$ airflow reduction to that duct. Only Box 9 showed a measurably better behavior to keep the airflow in balance with this restriction. A 20\% reduction in airflow was measured in Box 9. This test had a cooling coil directly before the box inlet at the exit of the AHU. The coil may have helped to balance any SP gradients that may have formed within the box.

Halving or doubling several duct runs had a mixed effect; the longer duct runs received less airflow, and the shorter duct runs received more airflow. Because several duct lengths were adjusted, any individual duct airflow was not impacted as significantly as the case with only one duct run modified.

Box 9 and Box 10 showed excellent airflow stability. In these cases, the fan was blowing the air across a cooling coil, which provided a more even inlet condition into the box. Because Box 9 showed the most balanced airflow, it was chosen to be connected to the mockup duct system.

Increasing the total airflow through the duct box did not cause a significant change in airflow balance between duct runouts except in Box 6, where the inlet conditions were laminar below 80 CFM and turbulent above 140 CFM. This was apparent in the measured data, as the relative airflow balance between each duct run varied significantly at the lower airflow rates when the flow transitioned from laminar to turbulent. This effect was not pronounced in the other boxes, because the air had to turn before exiting.

The results from the as-installed mockup indicate that relatively balanced airflow can be achieved under some reasonable set of design restrictions. These results suggest that a design 
guideline with simple strategies could be created if many permutations of duct lengths and bends are tested. In the tested duct layout, the minimum duct length was $9 \mathrm{ft}$ and the maximum duct length was $25 \mathrm{ft}$ with one or two elbows, and the airflow values ranged from 16 to $20 \mathrm{CFM}$. This is a reasonable expectation for the variations in branch duct airflows across a duct system. As shown in Figure 15, the total delivered energy was adequate for heating mode; in cooling mode, airflow was apparently insufficient to provide adequate cooling. However, the blower fan was not able to supply the correct maximum airflow for the cooling coil. A more powerful blower motor would be able to supply the necessary airflow to condition the space.

The measured results of this mockup suggest that one ducted unit can condition the entire second floor of this house, whereas a system using ductless MSHP head units would require a combination of three wall-mounted units to condition the space. Short duct runs and a compact layout result in an efficient system, despite the small duct diameter. The measured electric power needed to move the air in the mockup case ranged from 26 to 39 watts, for a fan watt draw of 0.16 to 0.22 watt/CFM. A fan watt draw of 0.5 watt/CFM is considered the cutoff for an efficient system. California's Title 24 specifies a minimum fan efficiency of $0.56 \mathrm{watt} / \mathrm{CFM}$. The manifold proved to be efficient, and even with a boost in airflow, the watt draw would be expected to remain below 0.5 watt/CFM. Static pressure also remained low at $51.5 \mathrm{~Pa}(0.20 \mathrm{in}$. water column).

A plot showing the duct curve for the mockup system, as well as several fan curves, also is shown in Figure 16 for comparison. The intersection of a fan curve and the duct curve is where a hypothetical system would operate. The mockup duct system would work with either a traditional or a high-velocity blower. 


\section{Conclusions}

The purpose of this project was to use laboratory measurements to determine if a small-diameter duct, home-run manifold air distribution system with additive zonal airflow could be feasible. Measurements show that under a reasonable set of system parameters, such a home-run system is feasible.

The research team tested ten manifold designs. The best-performing design, Box 9 with a wide inlet and outlet geometry, was chosen and used for testing with the mockup duct runout. The measured results showed a range of $+30 \%$ to $-20 \%$ airflow compared to the median airflow value for the mockup. If a reasonable set of conditions is applied to the data, such that a duct run should be longer than $10 \mathrm{ft}$ and shorter than $25 \mathrm{ft}$, the range of airflow values would fall within $+20 \%$ and $-10 \%$, which is an acceptable range for modern duct systems. Furthermore, Box 9 was designed to fit to existing ducted MSHP geometries and offers an easy method to bring this design to market.

The calculated thermal energy delivery for the mockup system compares favorably with the calculated load in heating mode. In cooling mode, the cooling capacity falls short, based on the airflow delivered by the test blower. However, the measured airflow was not up to the total rated airflow for the MSHP system. Based on measured results using a boost fan, if a higher-capacity MSHP blower was used, the cooling load could probably be met.

Total duct resistance is more important than outlet position on the box for a well-designed box. In the case of Box 9, outlet position had no measurable effect on the individual duct airflow. Ultimately, results from this study indicate that when one of the ideal manifold box designs is used, airflow from individual duct runs in this manifold system can be predictable, based on duct length and the number of elbows.

Future work could look at the following areas:

- Expand upon the mockup test case, and identify the complete range of duct runout configurations that provide adequately balanced airflow without additional balancing measures.

- Install the duct system in a test house, and measure the efficiency and ability of the system to provide comfort.

- Further consider the design and aesthetic implications of bringing small-diameter ductwork into conditioned space. An ideal design would require minimal use of obtrusive bulkheads and centrally locating the AHU and ductwork.

The goal of this project was to answer the following research questions. A brief summary answer is included after each research question.

- Can a strategy of additive, individual, small-diameter ducts (2-in. and 2.5-in. diameter) provide adequate airflow to give comfort in a low-load house? 
- The measured results indicate that the duct system can provide adequate airflow for heating mode. If the MSHP blower is slightly oversized, the total system can probably meet the cooling demand.

- What are the fan energy tradeoffs and maximum recommended run lengths for smalldiameter ducts connected to small plenums?

- The increased fan energy consumption expected from using smaller-diameter ductwork is minimized with smooth duct material and a compact duct design. The watt draw of the mockup duct system ranged from 0.16 to $0.22 \mathrm{watt} / \mathrm{CFM}$. Measured results also indicate that relatively balanced airflow can be achieved by using duct runouts longer than $9 \mathrm{ft}$ and shorter than $35 \mathrm{ft}$.

- What load characteristics could each duct serve, and what other parameters (velocity, throw) are associated with such a system?

- The duct system can deliver energy for a variety of load conditions, depending on the blower and connected coil. The mockup system can deliver 960 to $1,500 \mathrm{Btu} / \mathrm{h}$ per duct in heating mode and 740 to $1,170 \mathrm{Btu} / \mathrm{h}$ per duct in cooling mode, based on measured airflow rates. Qualitative visual analysis indicates the throw is similar to other high-velocity duct systems. Air velocities measured immediately before the duct outlet were 125 and $-2,000$ feet per minute for the tested airflow rates. Duct velocities for the mockup test case were 1,000 feet per minute $( \pm 150$ feet per minute) and represent expected system operation.

- What are the ideal configuration and geometry of a small plenum for a home-run smalldiameter duct system that would be adaptable to MSHP split systems or small distributed central systems and that would supply equal airflow through each duct without balancing?

- Two geometries ultimately showed the most airflow balance: (1) the geometry of Box 1 and Box 5 with a vertical row of outlets and a perpendicular inlet, and (2) the geometry of Box 9 with a wide and a narrow inlet and corresponding wide and narrow rows of outlets. Ultimately, the geometry proved to be less significant than the location of the box inlet relative to the duct outlets. The worst-performing designs had a small air inlet blowing directly into several outlets.

- What is the energy impact of locating ducts inside conditioned space relative to the higher fan energy needed to move the airflow under higher flow resistance?

- Throughout the project, the team determined that because of the shorter duct runs and smooth duct material, the manifold system does not result in duct resistances high enough to exclude the system from further investigation. The measured fan watt draw of 0.16 to 0.22 watt/CFM is on par with today's efficient systems. California's Title 24 requires forced-air systems to do better than 0.58 watt/CFM. Even with a more powerful blower, the fan energy consumption will probably not exceed the 0.58 watt/CFM threshold.

- Many studies have looked at the impact of bringing ductwork into conditioned space. Vineyard et al. (2003) measured an energy savings of $31 \%$ in heating and $36 \%$ in cooling for a traditional duct system. Further, the study found, for a high- 
velocity system, a $46 \%$ savings in heating and $35 \%$ savings in cooling by bringing ductwork from the attic into conditioned space. Because IBACOS found no energy penalty associated with the manifold duct system, no further investigation is warranted. 


\section{References}

AHRI. 2008. AHRI Standard 885-Procedure for Estimating Occupied Space Sound Levels in the Application of Air Terminals and Air Outlets. Arlington, VA: Air-Conditioning, Heating, and Refrigeration Institute.

Aldrich, R. 2009. "Efficient Houses with Minimal HVAC." Presented at the Northeast Sustainable Energy Association's Building Energy 2011 Conference, Boston, MA, March 2011. www.nesea.org/buildingenergy/bepresentations/.

Aldrich, R. 2010. Point-Source Heating Systems in Cold-Climate Homes: Wisdom Way Solar Village. Norwalk, CT: Steven Winter Associates, Inc.

ASHRAE. 2011. Handbook, HVAC Applications, Noise and Vibration Control. Atlanta, GA: ASHRAE.

Broniek, J. 2008. "Could a European Super Energy Efficient Standard Be Suitable for the U.S.?" Presented at the BEST1 Conference, Minneapolis, MN, June 2008. http://best1.thebestconference.org/program.htm.

Drost, K.M., and R.S. Wegeng. 1996. Distributed Space Conditioning for Residential Applications. Richland, WA: Pacific Northwest National Laboratory. http://eec.ucdavis.edu/ACEEE/1994-96/1996/VOL01/073.PDF.

Herk, A., and A. Rapport. 2015. Mini-Split Heat Pump Evaluation and Zero Energy Ready Home Support. Golden, CO: National Renewable Energy Laboratory, NREL/SR-5500-64855.

IBACOS. 2006a. KAAX-3-33410-11.A.2. Evaluation of Advanced Systems Research Plan. Pittsburgh, PA: IBACOS, April 2006 (unpublished).

IBACOS. 2006b. KAAX-3-33410-11.B.1. Evaluation of Advanced Systems Research Plan. Pittsburgh, PA: IBACOS, November 2006 (unpublished).

IBACOS. 2007. KAAX-3-33410-14.B.1. Evaluation of Advanced Systems Research Plan. Pittsburgh, PA: IBACOS, November 2007 (unpublished).

ICC. 2012. 2012 International Energy Conservation Code. Washington, DC: International Code Council.

Munson, B., D. Young, T. Okiishi, and W. Huebsch. 2009. Fundamentals of Fluid Mechanics, 6th edition. Hoboken, NJ: John Wiley \& Sons.

Poerschke, A. 2015. Modeled and Measured Performance of a Variable Airflow Volume SmallDiameter Duct System. Golden, CO: National Renewable Energy Laboratory.

Poerschke, A., and D. Stecher. 2014. Simplified Space Conditioning in Low-Load Homes: Results from Pittsburgh, Pennsylvania, New Construction Unoccupied Test House (Subcontract 
Report). Golden, CO: National Renewable Energy Laboratory, NREL/SR-550062122. www.nrel.gov/docs/fy14osti/62122.pdf.

Price. 2011. Air Distribution Engineering Guide. Suwanee, GA: Price Industries Limited.

Rittelmann, W. 2008. "Thermal Comfort Performance-Field Investigation of a Residential Forced-Air Heating and Cooling System with High Sidewall Supply Air Outlets." Presented at the BEST1 Conference, Minneapolis, MN, June 2008. http://best1.thebestconference.org/pdfs/045.pdf.

Rutkowski, H. 1997. Manual RS-Comfort, Air Quality, and Efficiency by Design. Arlington, VA: Air Conditioning Contractors of America.

Rutkowski, H. 2006. Manual J-Residential Load Calculation, 8th edition, Version 2. Arlington, VA: Air Conditioning Contractors of America.

Rutkowski, H. 2009. Manual D—Residential Duct Systems, 3rd edition, Version 1.00. Arlington, VA: Air Conditioning Contractors of America.

Stecher, D., K. Allison, and D. Prahl. 2012. Long-Term Results from Evaluation of Advanced New Construction Packages in Test Homes: Martha's Vineyard, Massachusetts (Subcontract Report). Golden, CO: National Renewable Energy Laboratory, NREL/SR-550054382. http://apps 1.eere.energy.gov/buildings/publications/pdfs/building america/test homes m arthavineyard.pdf.

Stecher, D., and A. Poerschke. 2013. Simplified Space Conditioning in Low-Load Homes: Results from Fresno, California, Retrofit Unoccupied Test House (Subcontract Report). Golden, CO: National Renewable Energy Laboratory, NREL/SR-550060712. www.nrel.gov/docs/fy14osti/60712.pdf.

Townsend, A., A. Rudd, and J. Lstiburek. 2009. Conference Paper 0908. “A Method for Modifying Ventilation Airflow Rates to Achieve Equivalent Occupant Exposure." Westford, MA: Building Science Press. www.buildingscience.com/documents/confpapers/cp-0908-ashraemodifying-ventilation-airflow.

Ueno, K., and H. Loomis. 2014. Long-Term Monitoring of Mini-Split Ductless Heat Pumps in the Northeast. Golden, CO: National Renewable Energy Laboratory.

Vineyard, E., R. Linkous, and E. Baskin. 2003. Measured Performance of Conventional and High-Velocity Distribution Systems in Attic and Space Locations. Atlanta, GA: ASHRAE.

Wrightsoft. Wrightsoft Right-Suite Universal, Version 13.0.10. Lexington, MA: Wrightsoft Corporation. 


\section{Appendix A: Flow Sensor Calibration}

The research team performed a comparative analysis to verify the consistency among the airvelocity sensors used in the laboratory test measurements. Table 7 presents the results of this analysis.

Table 7. Sensor Correction Factors

\begin{tabular}{|c|c|}
\hline Sensor & Correction (\%) \\
\hline $\mathbf{1 0}$ & 2.2343 \\
$\mathbf{1 1}$ & -3.2512 \\
$\mathbf{1 2}$ & -1.2128 \\
$\mathbf{1 3}$ & 0.3681 \\
$\mathbf{1 4}$ & -1.1798 \\
$\mathbf{1 5}$ & 0.0466 \\
$\mathbf{1 6}$ & 12.7841 \\
\hline
\end{tabular}

To arrive at these values, all data from each sensor were considered. The team then used various statistical tests to determine extreme outliers that were causing a skew in the readings. The values that proved to be outliers were omitted from further mean bias calculations. A mean percent deviation from the median value for each sensor was calculated and is shown in Table 7.

To understand the relationship between the air velocity reading and volumetric flow rate, the team conducted the following test. A single air velocity sensor was inserted into a 2-in.-diameter duct run and connected to a Duct Blaster. The Duct Blaster was set to a volumetric flow rate, and the corresponding air velocity was measured. The measured air velocity values were then multiplied by the area of the duct to determine the volumetric flow rate. The calculated flow rate was then multiplied by 0.85 to compensate for the shape of the velocity profile. These three flow rate values are compared in Table 8. Measured velocities were taken in the center of the duct, thus overestimating the volumetric flow rate before the correction factor was applied.

Table 8. Velocity Measurement and Calculation Comparison

\begin{tabular}{c|c|c|c|c|c}
\hline Duct Blaster CFM & $\mathbf{3 0}$ & $\mathbf{2 5}$ & $\mathbf{2 0}$ & $\mathbf{1 5}$ & $\mathbf{1 0}$ \\
\hline Velocity Sensor Measurement (FPM) & 1,580 & 1,360 & 1,120 & 870 & 650 \\
Calculated CFM & 35 & 29 & 25 & 19 & 14 \\
Calculated CFM with Velocity Profile & 29 & 25 & 21 & 16 & 12 \\
Correction (0.85) & $-2 \%$ & $0 \%$ & $4 \%$ & $7 \%$ & $20 \%$ \\
\hline
\end{tabular}

In addition to insertion depth, the angle of the probe could have an impact on the measured velocity. The minimal impact of rotating the velocity probe by $15^{\circ}$ clockwise and $15^{\circ}$ counterclockwise is shown in Table 9. 
Table 9. Sensitivity of Flow Measurement to Sensor Angle

\begin{tabular}{c|c|c}
\hline $\begin{array}{c}\text { Insertion Angle } \\
(\mathbf{d e g})\end{array}$ & $\begin{array}{c}\text { Measured Velocity } \\
(\mathbf{m} / \mathbf{s})\end{array}$ & $\begin{array}{c}\text { \% Difference } \\
\text { from } \mathbf{0}^{\circ}\end{array}$ \\
\hline $\mathbf{0}$ & 7.1 & - \\
$\mathbf{5}$ & 7.11 & 0.14 \\
$\mathbf{1 0}$ & 7.1 & 0.00 \\
$\mathbf{1 5}$ & 7.11 & 0.14 \\
$\mathbf{- 5}$ & 7.06 & -0.56 \\
$\mathbf{- 1 0}$ & 7.02 & -1.13 \\
$\mathbf{- 1 5}$ & 6.93 & -2.39 \\
\hline
\end{tabular}




\section{Appendix B: Test Volumetric Flow Rate and Velocity Data}

Table 10 through Table 19 present the corrected velocity and calculated flow rate data for the 10 mockup plenum boxes tested. The value listed in the "Control" setting represents the fan controller value. This value is arbitrary and is listed only for reference.

Table 10. Box 1 Raw Data

\begin{tabular}{|c|c|c|c|c|c|c|c|c|c|c|c|c|c|c|}
\hline CFM & 246 & & 216 & & 182 & & 147 & & 107 & & 70 & & 35 & \\
\hline Control & \multicolumn{2}{|c|}{35} & \multicolumn{2}{|c|}{30} & \multicolumn{2}{|c|}{25} & \multicolumn{2}{|c|}{20} & \multicolumn{2}{|c|}{15} & \multicolumn{2}{|c|}{10} & \multicolumn{2}{|c|}{5} \\
\hline Duct & CFM & FPM & CFM & FPM & CFM & FPM & CFM & FPM & CFM & FPM & CFM & FPM & CFM & FPM \\
\hline 1 & 36 & 1.630 & 31 & 1,430 & 26 & 1,197 & 21 & \begin{tabular}{|l|l|}
980 \\
\end{tabular} & 16 & 712 & 10 & 459 & 5 & 230 \\
\hline 2 & 35 & 1,612 & 30 & 1,388 & 26 & 1,176 & 21 & \begin{tabular}{|l}
941 \\
941
\end{tabular} & 15 & 690 & 10 & 454 & 5 & 230 \\
\hline 3 & 36 & 1,651 & 31 & 1,415 & 26 & 1,190 & 21 & 958 & 15 & 691 & 10 & 455 & 5 & 228 \\
\hline 4 & 35 & 1,603 & 30 & 1,371 & 25 & 1,157 & 21 & 956 & 15 & 684 & 10 & 446 & 5 & 227 \\
\hline 5 & 37 & 1,674 & 31 & 1,434 & 26 & 1,210 & 21 & 966 & 15 & 704 & 10 & 458 & 5 & 229 \\
\hline 6 & 36 & 1,662 & 31 & 1,420 & 26 & 1,207 & 21 & 976 & 15 & 709 & 10 & 463 & 5 & 225 \\
\hline 7 & 32 & 1,454 & 31 & 1,441 & 26 & 1,191 & 21 & 965 & 16 & 716 & 10 & 461 & 5 & 219 \\
\hline
\end{tabular}

Table 11. Box 2 Raw Data

\begin{tabular}{|c|c|c|c|c|c|c|c|c|c|c|c|c|c|c|}
\hline CFM & 175 & & 152 & & 126 & & 98 & & 73 & & 48 & & 26 & \\
\hline Control & \multicolumn{2}{|c|}{35} & \multicolumn{2}{|c|}{30} & \multicolumn{2}{|c|}{25} & \multicolumn{2}{|c|}{20} & \multicolumn{2}{|c|}{15} & \multicolumn{2}{|c|}{10} & \multicolumn{2}{|c|}{5} \\
\hline Duct & CFM & FPM & CFM & FPM & CFM & FPM & CFM & FPM & CFM & FPM & CFM & FPM & CFM & FPM \\
\hline 1 & 21 & 972 & 18 & 834 & 15 & 694 & 12 & 542 & 9 & 407 & 6 & 275 & 3 & 147 \\
\hline 2 & 23 & 1,059 & 20 & 912 & 16 & 753 & 13 & 600 & 10 & 452 & 7 & 303 & 4 & 165 \\
\hline 3 & 24 & 1,108 & 21 & 963 & 17 & 792 & 14 & 622 & 10 & 462 & 7 & 309 & 4 & 164 \\
\hline 4 & 27 & 1,225 & 23 & 1,056 & 19 & 873 & 15 & 680 & 11 & 501 & 7 & 330 & 4 & 174 \\
\hline 5 & 29 & 1,315 & 25 & 1,143 & 21 & 947 & 16 & 742 & 12 & 553 & 8 & 354 & 4 & 189 \\
\hline 6 & 28 & 1,272 & 24 & 1,096 & 20 & 917 & 15 & 709 & 11 & 521 & 7 & 335 & 4 & 185 \\
\hline 7 & 24 & 1,085 & 21 & 950 & 17 & 799 & 13 & 617 & 10 & 455 & 6 & 292 & 4 & 167 \\
\hline
\end{tabular}

Table 12. Box 3 Raw Data

\begin{tabular}{|c|c|c|c|c|c|c|c|c|c|c|c|c|c|c|}
\hline CFM & 210 & & 182 & & 153 & & 121 & & 88 & & 57 & & 30 & \\
\hline Control & \multicolumn{2}{|c|}{35} & \multicolumn{2}{|c|}{30} & \multicolumn{2}{|c|}{25} & \multicolumn{2}{|c|}{20} & \multicolumn{2}{|c|}{15} & \multicolumn{2}{|c|}{10} & \multicolumn{2}{|c|}{5} \\
\hline Duct & CFM & FPM & CFM & FPM & CFM & FPM & CFM & FPM & CFM & FPM & CFM & FPM & CFM & FPM \\
\hline 1 & 28 & 1,280 & 24 & 1,117 & 21 & 958 & 16 & 746 & 12 & 541 & 8 & 355 & 4 & 195 \\
\hline 2 & 28 & 1,271 & 24 & 1,104 & 20 & 936 & 16 & 736 & 12 & 549 & 8 & 356 & 4 & 172 \\
\hline 3 & 28 & 1,286 & 25 & 1,130 & 21 & 944 & 16 & 732 & 12 & 543 & 7 & 337 & 4 & 189 \\
\hline 4 & 30 & 1,377 & 26 & 1,188 & 22 & 1,004 & 17 & 792 & 13 & 576 & 8 & 375 & 4 & 193 \\
\hline 5 & 32 & 1,466 & 28 & 1,283 & 23 & 1,057 & 18 & 836 & 13 & 608 & 9 & 391 & 5 & 209 \\
\hline 6 & 33 & 1,500 & 28 & 1,304 & 24 & 1,092 & 19 & 861 & 14 & 629 & 9 & 400 & 4 & 205 \\
\hline 7 & 32 & 1,447 & 27 & 1,233 & 22 & 1,030 & 18 & 841 & 13 & 601 & 9 & 392 & 4 & 200 \\
\hline
\end{tabular}


Table 13. Box 4 Raw Data

\begin{tabular}{|c|c|c|c|c|c|c|c|c|c|c|c|c|c|c|}
\hline CFM & 227 & & 200 & & 168 & & 134 & & 100 & & 65 & & 32 & \\
\hline Control & \multicolumn{2}{|c|}{35} & \multicolumn{2}{|c|}{30} & \multicolumn{2}{|c|}{25} & \multicolumn{2}{|c|}{20} & \multicolumn{2}{|c|}{15} & \multicolumn{2}{|c|}{10} & \multicolumn{2}{|c|}{5} \\
\hline Duct & CFM & FPM & CFM & FPM & CFM & FPM & CFM & FPM & CFM & FPM & CFM & FPM & CFM & FPM \\
\hline 1 & 33 & 1,524 & 29 & 1,319 & 24 & 1,103 & 20 & 901 & 14 & 647 & 9 & 428 & 5 & 210 \\
\hline 2 & 29 & 1,314 & 25 & 1,140 & 21 & 955 & 17 & 765 & 12 & 569 & 8 & 378 & 4 & 191 \\
\hline 3 & 34 & 1,566 & 30 & 1,364 & 25 & 1,146 & 19 & 892 & 15 & 688 & 10 & 442 & 5 & 223 \\
\hline 4 & 36 & 1,665 & 32 & 1,460 & 27 & 1,235 & 22 & 997 & 16 & 740 & 10 & 471 & 5 & 226 \\
\hline 5 & 28 & 1,262 & 24 & 1,107 & 20 & 927 & 16 & 735 & 12 & 546 & 8 & 357 & 4 & 190 \\
\hline 6 & 35 & 1,617 & 30 & 1,387 & 26 & 1,170 & 20 & 917 & 15 & 696 & 10 & 440 & 5 & 215 \\
\hline 7 & 32 & 1,456 & 31 & 1,410 & 26 & 1,177 & 21 & 953 & 15 & 702 & 10 & 445 & 4 & 205 \\
\hline
\end{tabular}

Table 14. Box 5 Raw Data

\begin{tabular}{|c|c|c|c|c|c|c|c|c|c|c|c|c|c|c|}
\hline CFM & 340 & & 295 & & 247 & & 195 & & 142 & & 92 & & 43 & \\
\hline Control & \multicolumn{2}{|c|}{35} & \multicolumn{2}{|c|}{30} & \multicolumn{2}{|c|}{25} & \multicolumn{2}{|c|}{20} & \multicolumn{2}{|c|}{15} & \multicolumn{2}{|c|}{10} & \multicolumn{2}{|c|}{5} \\
\hline Duct & CFM & FPM & CFM & FPM & CFM & FPM & CFM & FPM & CFM & FPM & CFM & FPM & CFM & FPM \\
\hline 1 & 45 & 1,334 & 39 & 1,155 & 33 & 974 & 26 & 761 & 19 & 557 & 12 & 365 & 6 & 171 \\
\hline 2 & 46 & 1,352 & 40 & 1,166 & 33 & 980 & 26 & 769 & 19 & 562 & 13 & 370 & 6 & 174 \\
\hline 3 & 51 & 1,482 & 43 & 1,273 & 37 & 1,072 & 29 & 840 & 21 & 607 & 13 & 393 & 6 & 182 \\
\hline 4 & 49 & 1,432 & 42 & 1,242 & 35 & 1,039 & 28 & 818 & 20 & 598 & 13 & 385 & 6 & 179 \\
\hline 5 & 50 & 1,468 & 43 & 1,262 & 36 & 1,047 & 28 & 824 & 20 & 593 & 13 & 384 & 6 & 177 \\
\hline 6 & 50 & 1,457 & 43 & 1,267 & 36 & 1,061 & 28 & 829 & 21 & 604 & 14 & 400 & 6 & 186 \\
\hline 7 & 50 & 1,454 & 44 & 1,286 & 37 & 1,085 & 30 & 885 & 22 & 639 & 14 & 405 & 6 & 190 \\
\hline
\end{tabular}

Table 15. Box 6 Raw Data

\begin{tabular}{|c|c|c|c|c|c|c|c|c|c|c|c|c|c|c|}
\hline CFM & 196 & & 169 & & 140 & & 112 & & 83 & & 56 & & 33 & \\
\hline Control & \multicolumn{2}{|c|}{35} & \multicolumn{2}{|c|}{30} & \multicolumn{2}{|c|}{25} & \multicolumn{2}{|c|}{20} & \multicolumn{2}{|c|}{15} & \multicolumn{2}{|c|}{10} & \multicolumn{2}{|c|}{5} \\
\hline Duct & CFM & FPM & CFM & FPM & CFM & FPM & CFM & FPM & CFM & FPM & CFM & FPM & CFM & FPM \\
\hline 1 & 25 & 733 & 21 & 627 & 18 & 523 & 14 & 425 & 11 & 322 & 8 & 222 & 5 & 134 \\
\hline 2 & 23 & 685 & 20 & 593 & 17 & 495 & 14 & 409 & 10 & 304 & 7 & 215 & 5 & 136 \\
\hline 3 & 23 & 669 & 20 & 577 & 16 & 481 & 13 & 393 & 10 & 292 & 7 & 201 & 4 & 125 \\
\hline 4 & 24 & 707 & 21 & 603 & 17 & 496 & 14 & 407 & 10 & 304 & 7 & 214 & 5 & 133 \\
\hline 5 & 27 & 782 & 23 & 662 & 19 & 546 & 15 & 435 & 11 & 320 & 7 & 214 & 5 & 137 \\
\hline 6 & 39 & 1,142 & 34 & 989 & 28 & 831 & 22 & 643 & 17 & 488 & 11 & 320 & 6 & 167 \\
\hline 7 & 35 & 1,027 & 31 & 902 & 25 & 726 & 20 & 574 & 14 & 407 & 9 & 269 & 5 & 148 \\
\hline
\end{tabular}


Table 16. Box 7 Raw Data.

\begin{tabular}{|c|c|c|c|c|c|c|c|c|c|c|c|c|c|c|}
\hline CFM & 276 & & 238 & & 197 & & 154 & & 116 & & 75 & & 38 & \\
\hline Control & \multicolumn{2}{|c|}{35} & \multicolumn{2}{|c|}{30} & \multicolumn{2}{|c|}{25} & \multicolumn{2}{|c|}{20} & \multicolumn{2}{|c|}{15} & \multicolumn{2}{|c|}{10} & \multicolumn{2}{|c|}{5} \\
\hline Duct & CFM & FPM & CFM & FPM & CFM & FPM & CFM & FPM & CFM & FPM & CFM & FPM & CFM & FPM \\
\hline 1 & 35 & 1,023 & 30 & 894 & 25 & 741 & 20 & 573 & 15 & 430 & 10 & 283 & 5 & 147 \\
\hline 2 & 36 & 1,058 & 31 & 919 & 26 & 762 & 20 & 593 & 15 & 449 & 10 & 294 & 6 & 167 \\
\hline 3 & 38 & 1,118 & 33 & 971 & 27 & 803 & 21 & 629 & 16 & 467 & 10 & 307 & 5 & 150 \\
\hline 4 & 41 & 1,205 & 35 & 1,037 & 29 & 848 & 23 & 671 & 17 & 493 & 11 & 329 & 5 & 159 \\
\hline 5 & 44 & 1,279 & 37 & 1,097 & 31 & 907 & 24 & 710 & 18 & 529 & 11 & 330 & 6 & 169 \\
\hline 6 & 42 & 1,229 & 36 & 1,059 & 29 & 853 & 23 & 674 & 18 & 520 & 11 & 328 & 6 & 165 \\
\hline 7 & 41 & 1,193 & 35 & 1,016 & 29 & 851 & 23 & 671 & 17 & 509 & 11 & 315 & 6 & 167 \\
\hline
\end{tabular}

Table 17. Box 8 Raw Data

\begin{tabular}{|c|c|c|c|c|c|c|c|c|c|c|c|c|c|c|}
\hline CFM & 266 & & 233 & & 194 & & 153 & & 111 & & 74 & & 38 & \\
\hline Control & \multicolumn{2}{|c|}{35} & \multicolumn{2}{|c|}{30} & \multicolumn{2}{|c|}{25} & \multicolumn{2}{|c|}{20} & \multicolumn{2}{|c|}{15} & \multicolumn{2}{|c|}{10} & \multicolumn{2}{|c|}{5} \\
\hline Duct & CFM & FPM & CFM & FPM & CFM & FPM & CFM & FPM & CFM & FPM & CFM & FPM & CFM & FPM \\
\hline 1 & 34 & 1,565 & 30 & 1,382 & 25 & 1,127 & 20 & 896 & 15 & 687 & 10 & 463 & 5 & 237 \\
\hline 2 & 40 & 1,811 & 35 & 1,604 & 29 & 1,325 & 23 & 1,040 & 18 & 806 & 12 & 548 & 6 & 266 \\
\hline 3 & 38 & 1,731 & 31 & 1,428 & 27 & 1,257 & 21 & 946 & 14 & 640 & 9 & 411 & 5 & 242 \\
\hline 4 & 42 & 1,932 & 37 & 1,680 & 31 & 1,431 & 24 & 1,092 & 17 & 768 & 11 & 519 & 6 & 272 \\
\hline 5 & 38 & 1,741 & 33 & 1,504 & 28 & 1,261 & 22 & 1,017 & 16 & 745 & 11 & 482 & 5 & 241 \\
\hline 6 & 30 & 1,384 & 28 & 1,262 & 24 & 1,093 & 19 & 858 & 12 & 541 & 8 & 372 & 5 & 214 \\
\hline 7 & 44 & 2,018 & 39 & 1,807 & 31 & 1,419 & 25 & 1,149 & 20 & 897 & 13 & 590 & 6 & 270 \\
\hline
\end{tabular}

Table 18. Box 9 Raw Data

\begin{tabular}{|c|c|c|c|c|c|c|}
\hline CFM & 138 & & 145 & & 148 & \\
\hline Control & \multicolumn{2}{|c|}{ Low } & \multicolumn{2}{|c|}{ Medium } & \multicolumn{2}{|c|}{ High } \\
\hline Duct & CFM & FPM & CFM & FPM & CFM & FPM \\
\hline 1 & 20 & 904 & 21 & 954 & 21 & 982 \\
\hline 2 & 20 & 908 & 21 & 949 & 21 & 972 \\
\hline 3 & 19 & 890 & 21 & 942 & 21 & 959 \\
\hline 4 & 20 & 908 & 21 & 966 & 21 & 981 \\
\hline 5 & 19 & 888 & 20 & 935 & 21 & 962 \\
\hline 6 & 20 & 911 & 21 & 964 & 21 & 981 \\
\hline 7 & 19 & 893 & 20 & 934 & 21 & 947 \\
\hline
\end{tabular}


Table 19. Box 10 Raw Data

\begin{tabular}{c|c|c|c|c|c|c}
\hline CFM & $\mathbf{1 3 9}$ & & $\mathbf{1 5 4}$ & & $\mathbf{1 6 1}$ & \\
\hline Control & \multicolumn{2}{|c|}{ Low } & \multicolumn{2}{c|}{ Medium } & \multicolumn{2}{c}{ High } \\
\cline { 2 - 7 } Duct & CFM & FPM & CFM & FPM & CFM & FPM \\
\hline $\mathbf{1}$ & 20 & 927 & 22 & 1,019 & 23 & 1,065 \\
$\mathbf{2}$ & 20 & 922 & 22 & 1,025 & 24 & 1,078 \\
$\mathbf{3}$ & 20 & 904 & 22 & 1,000 & 23 & 1,042 \\
$\mathbf{4}$ & 19 & 870 & 21 & 959 & 22 & 991 \\
$\mathbf{5}$ & 20 & 919 & 22 & 1,020 & 23 & 1,070 \\
$\mathbf{6}$ & 19 & 854 & 21 & 962 & 22 & 996 \\
$\mathbf{7}$ & 21 & 985 & 24 & 1,082 & 25 & 1,133 \\
\hline
\end{tabular}


buildingamerica.gov

\section{U.S. DEPARTMENT OF Energy Efficiency \& Nㅡㄹ Renewable Energy}

